\title{
The Dynamics of Marriage and Divorce
}

\author{
Gustaf Bruze, Aarbus University \\ Michael Svarer, Aarbus University
}

Yoram Weiss, Tel-Aviv University

\begin{abstract}
We formulate and estimate a dynamic model of marriage, divorce, and remarriage using panel data on two cohorts of Danish men and women. The marital surplus is identified from the probability of divorce and the surplus shares of husbands and wives from their willingness to enter marriage. We find that the educations of husbands and wives are complements. Education raises the share of the marital surplus for men but not for women. As men and women get older, husbands receive a larger share of the marital surplus. The estimated costs of divorce are high both early and late in marriage.
\end{abstract}

\section{Introduction}

Modern marriage markets are characterized by high turnover; men and women divorce more but also remarry more than in the past. However, different individuals have different marital histories; they marry, divorce,

We thank the Danish Social Science Research Foundation, the Danish Council for Independent Research in Social Sciences, and the Cycles, Adjustment, and Policy Research Unit (CAP) at Aarhus University for financial support. We also thank Rune Vammen Lesner and Jonas Maibom Pedersen for excellent research assistance. Finally, we thank Jerome Adda, B. J. Christensen, John Knowles, Dale Mortensen, Victor Rios-Rull, Jean-Marc Robin, and Aloysius Siow for useful comments on previous drafts. Contact the corresponding author, Yoram Weiss, at weiss@post.tau ac.il. Information concerning access to the data used in this article is available as supplementary material online.

[Journal of Labor Economics, 2015, vol. 33, no. 1]

(C) 2014 by The University of Chicago. All rights reserved. 0734-306X/2015/3301-0005\$10.00

Submitted March 31, 2013; Accepted August 8, 2013; Electronically published October 31, 2014 
and remarry at different rates. To explain this variation it is crucial to understand the two-sided aspect of marriage markets. Marriages form and dissolve based on preferences and expectations of two different individuals who operate in a "marriage market" with many competing agents.

In this paper, we examine the marriage patterns of two Danish cohorts, which we follow from 1980 to 2006 . We focus on marriage patterns by completed education and potential previous marriages and consider two alternative definitions of unions: marriages and partnerships, which include both marriages and cohabitation.

We first document which types of individuals are more likely to marry, to stay married, and to remarry and which types of marriages are more stable. Similar to previous studies, we find that Danish men and women tend to marry partners with an education similar to their own. A novel aspect of our work is to show that this positive sorting appears gradually as men and women are selected into and out of marriage on the basis of their education. Most noticeably, we find that men with low education are slowly sorted out of the marriage market and remain single. The main force behind this process is that marriages in which both partners or only the husband have low education dissolve at a considerably higher rate than other marriages.

We then proceed by formulating and estimating a dynamic two-sided matching model with transferable utility. The model and the rich panel data that we use make it possible for us to estimate the total marital surplus in different types of marriages, the shares of the surplus that husbands and wives receive, the effects of selection on divorce, and the costs of divorce as a function of marital duration. Our main identification strategy relies on the fact that there is a one-to-one relationship between divorce rates and the size of the marital surplus, net of the cost of divorce, in models with transferable utility (Becker, Landes, and Michael 1977). We can therefore use the divorce probabilities in our sample to identify the total marital surplus in different types of marriages. Furthermore, we assume that men and women are forward-looking and enter the marriages that give them the highest utility. This allows us to use the entry rates of single men and women into different types of marriages to identify the shares of the surplus that husbands and wives receive in those marriages (a higher share for husbands raises the entry rates of single men and lowers the entry rates of single women).

The strength of our paper is that we are able to use all the marital decisions of all men and women in two entire Danish cohorts over a 27 -year period to estimate a small number of parameters that govern the dynamics of marriage and divorce. Some of the results that we obtain through this revealed-preference approach are related to marital patterns in our data that are easy to document. For example, we find that education raises the marital surplus when both spouses have the same education, which is consis- 
tent with the low divorce rates for highly educated couples. The majority of our results, however, can only be recovered with a dynamic two-sided matching model. For example, we find that the education of men has a large impact on the share of the marital surplus that men receive and that the education of men raises the male share of the marital surplus. In contrast, the education of women has a smaller impact on the share of the marital surplus that women receive, and it is women with medium education who receive the largest share of the marital surplus. We also find that the educations of husbands and wives are complements in marriage. Furthermore, the costs of divorce are large and exceed half of the total capitalized value of an ongoing marriage. Finally, we find that the high rates of divorce in second marriages are mostly a result of dynamic selection as men and women with a weaker preference for marriage are more likely to divorce and then remarry.

This paper builds on previous works by Choo and Siow (2006) and Chiappori, Salanie, and Weiss (2011) that estimate static models of matching by education. In these papers, the total marital surplus and the surplus shares of husbands and wives are identified and estimated with data on the fraction of men and women of different types who are married to different types of partners at given points in time. In contrast, this paper uses panel data on both the entry rates of single men and women into marriage and the divorce probabilities of married couples to identify and estimate the marital surplus and the surplus shares of husbands and wives. Our Danish registry data thus provide additional variation across individuals that we exploit to identify and estimate the parameters of our matching model. In this respect, our paper is most similar to Choo and Siow (2007), which formulates and estimates a dynamic model of marriage with time-varying sex ratios; Choo (2012), which constructs a dynamic model of matching by age; and Jacquemet and Robin (2012), which studies matching by wages in a search framework. ${ }^{1}$

More generally, our paper is related to several previous studies in the marriage matching literature, such as Brien, Lillard, and Stern (2006), which estimates a model of marital transitions for women in the United States including learning about match quality, children as an exogenous event, and a three-way choice between singlehood, cohabitation, and marriage. Another early paper in this vein is Aiyagari, Greenwood, and Guner (2000), which constructs a dynamic model of marriage and divorce and uses calibration to evaluate the impact of policies such as child support. Recent papers by Mazzoco, Ruiz, and Yamaguchi (2007), Seitz (2009), and Gemici and Laufer (2011) extend this work and estimate two-sided dynamic models of family decisions including marriage and divorce, as well as saving and labor

\footnotetext{
${ }^{1}$ The model of Choo and Siow (2007) is also presented and discussed in Siow (2008).
} 
supply. Siow (2009) investigates the supermodularity of the marital surplus function in the context of a static marriage matching model, and Graham (2011) surveys empirical models that are used to study assignment problems with complementarities and social spillovers.

Our paper is also related to the collective household literature (Chiappori 1988; Browning et al. 1994), which takes the set of married couples as given and uses data on assignable goods such as private consumption and leisure to analyze how the characteristics of husbands and wives affect intrahousehold allocations. In the Danish context, Browning and Bonke (2006) and Browning and Gørtz (2012) have used data on the private consumption and leisure of Danish husbands and wives to estimate intrahousehold sharing rules. In contrast, our paper uses the choices of Danish men and women to enter into and exit out of marriage to estimate both the total surplus in marriage and how this surplus is divided between husbands and wives. One advantage of the collective approach is that the sharing rule can be expressed in monetary units. One advantage of the approach we pursue in this paper is that the sharing rule is identified from the choices of single men and women to enter into marriage and, arguably, incorporates all the aspects of a marriage that are relevant to men and women (not only their consumption and leisure). In many ways, our results are similar to those found in the collective literature, but there are also important differences, which we discuss below.

We proceed by first describing our unique Danish data in terms of the matching patterns by education within a cohort as it ages. We provide details on the transitions between marriage, divorce, and remarriage, separating first and second marriages. We then describe the model and highlight the main assumptions. Finally, we present and discuss the estimated parameters, the marital output flow, the marital surplus, and the shares of the marital surplus received by husband and wives.

\section{Data}

\section{A. The Sample}

The data we use are based on registries administered by Statistics Denmark that follow all Danish residents from 1980 to 2006. We first fix the initial age of men and women in 1980 to 20 years and examine all men and women born in 1960. We then compute the median age difference between husbands and wives in all marriages over the period 1980-2006 in which at least one of the two spouses was born in 1960. This median age difference is 2 years. We therefore construct our sample so that it contains men born in 1960 and women born in 1962. Thus, we follow men over the age range of 20-46 years of age and women over the age range of 18-44 years of age. By constructing the sample in this way, we implicitly control for age differences in marriage, and we come closer to an equilibrium concept in 
the marriage market as we work with men and women who tend to marry each other.

Although all men and women in our sample belong to only two cohorts, it is worth emphasizing that we include observations for all marriages in the likelihood function when we estimate our structural model. Stated differently, we include observations for men born in 1960 and women born in 1962 in the likelihood function, regardless of whether these men and women married members of the other cohort (with an age difference between the husband and the wife of 2 years) or married a spouse from a different cohort (with an age difference between the husband and the wife of more or less than 2 years).

The Danish registry data only include men and women who are living in Denmark in a given year. In order to obtain complete marital histories for all the individuals in our sample, we therefore require that men and women lived in Denmark during the entire sample period 1980-2006. This restriction gives us an initial sample of 65,167 men and women. ${ }^{2}$ We exclude 1,591 men and women who have missing educational data or who are married to or cohabiting with a partner with missing educational data. We also exclude 420 men and women who are classified as immigrants. Finally, we exclude 725 individuals who were already married in 1980 (371 men and 354 women). ${ }^{3}$ This gives us a final sample of 62,431 men and women.

\section{B. Definition of Marriage and Partnerships}

The registry data from Statistics Denmark contain information on whether or not a man and a woman are legally married to each other and whether or not they are cohabiting. The data on legal marriage is taken directly from population registries with the official marital status of all Danish residents. To be classified as cohabiting by Statistics Denmark, a man and a woman must share an address, cannot be related, and can have an age difference of at most 15 years. This measure of cohabitation is likely to contain some noise, since, for example, a male student and a female student of the same age who share a flat but who are not in a relationship will be registered as cohabiting.

In this paper, we consider a man and a woman as married to each other if the man and the woman are legally married and live together. The only exception we allow for is if a man and a woman are legally married to each other for at least 4 consecutive years but do not live together for at most

${ }^{2}$ An additional 23,023 individuals (men born in 1960 or women born in 1962) were registered as living in Denmark in at least one of the years 1980-2006 but did not live in the country for the entire period. Many of these individuals are immigrants who entered Denmark after 1980.

${ }^{3}$ We treat a man and a woman as married if they are legally married to each other and live together. 
2 intermediate years. In this case, we treat the couple as married for the entire 4-year period. Such examples occur in the data when a man and a woman who are legally married temporarily live apart as one spouse is working or studying away from home. In our sample, there are a total of 1,963 cases in which we extended our definition of marriage to couples who were temporarily living apart. Furthermore, we consider a man and a woman as being in a partnership if they are married according to our definition above or cohabiting according to the definition of Statistics Denmark. ${ }^{4}$

In the baseline estimation of our dynamic matching model, we divide men and women into those who are single and those who are married (not including cohabitation). As a robustness check, we also estimate our model after dividing men and women into those who are single and those who are in a partnership (married or cohabiting). We do not try to model the cohabitation decision explicitly, and a three-state model with cohabitation as a separate choice is left for future work.

\section{Education Groups}

We divide all the men and women in our sample into three groups based on their level of completed education in 2006: high school or less, vocational education, and college (defined as some college or more). Table 1 shows the distribution of men and women in our sample by these levels of education. As can be seen in the table, there are about an equal number of men and women in our sample. However, the distribution by education differs between men and women. We see that the proportion with high school (or less) and with vocational education is higher for men, whereas the proportion with some college (or more) is higher for women. Overall, the women in our sample are thus slightly more educated than the men in the sample.

\section{Children}

The registry data also contain information on the children of each of the men and women in our sample. Including children and fertility decisions in our analysis would put a heavy additional load on our model. In addition, the data on children are incomplete in the sense that it is sometimes difficult to infer where children are living. In the data, each person can only be registered as living at a single address. Yet it is well known that many children of divorced parents in Denmark spend approximately half

\footnotetext{
${ }^{4}$ There are different legal implications of cohabitation vis-à-vis legal marriage. In some respects, couples who cohabited for more than 2 years are considered as married. For instance, the law stipulates that if a couple has cohabited for more than 2 years in an apartment and the partner who originally rented the apartment dies, the surviving partner has the right to keep the apartment.
} 
The Dynamics of Marriage and Divorce

129

Table 1

Sample Distribution of Male and Female Completed Education

\begin{tabular}{lcc}
\hline Completed Education (at Age 46) & Men & Women \\
\hline High school or less & .32 & .27 \\
Vocational education & .44 & .41 \\
Some college or more & .24 & .32 \\
No. of observations & 31,192 & 31,239 \\
\hline
\end{tabular}

the time with their mother and the rest of their time with their father. Thus, we cannot distinguish cases where children spend all their time with one parent (typically the mother) from cases where children divide their time equally between the two parents. For these reasons, we choose not to include children explicitly in our analysis.

\section{Marriage Patterns}

\section{A. Marriage and Cohabitation}

In figures 1-3, we describe our sample by showing the fraction of men and women in marriages and partnerships, the hazards of entry into first marriages and partnerships, and the divorce hazards for first marriages and partnerships. These figures illustrate that cohabitation is a very common phenomenon in Denmark and that most initial partnerships involve cohabitation. ${ }^{5}$ Toward the end of our sample, when men and women reach their mid-forties, this pattern is reversed, and most partnerships are marriages. The hazards of entry into first partnerships are initially much larger than the hazards of entry into first marriage, and the divorce hazards for first partnerships are much larger than the divorce hazards for first marriage.

In figure $4 A$, we show the proportion of men and women who are married by level of education. At early ages, women with medium education have the highest rates of marriage. Highly educated men and women delay their entry into marriage, but by the end of our sample, they are the most likely to be married. ${ }^{6}$ In figure $4 B$, we show the proportion of men and women who are cohabiting without being married by level of education.

${ }^{5}$ Svarer (2004) reports that more than $60 \%$ of all young couples are cohabitants.

${ }^{6}$ A similar pattern of first marriages occurring after the completion of schooling is also present in the United States (see Copen et al. 2012). A potential explanation of this behavior is that investments in schooling not only generate returns in the labor market but also improve marriage market prospects (see Chiappori et al. 2011). It is therefore efficient to delay marriage until the completion of schooling. Ge (2011) estimates a model that combines endogenous marriage and schooling decisions. 


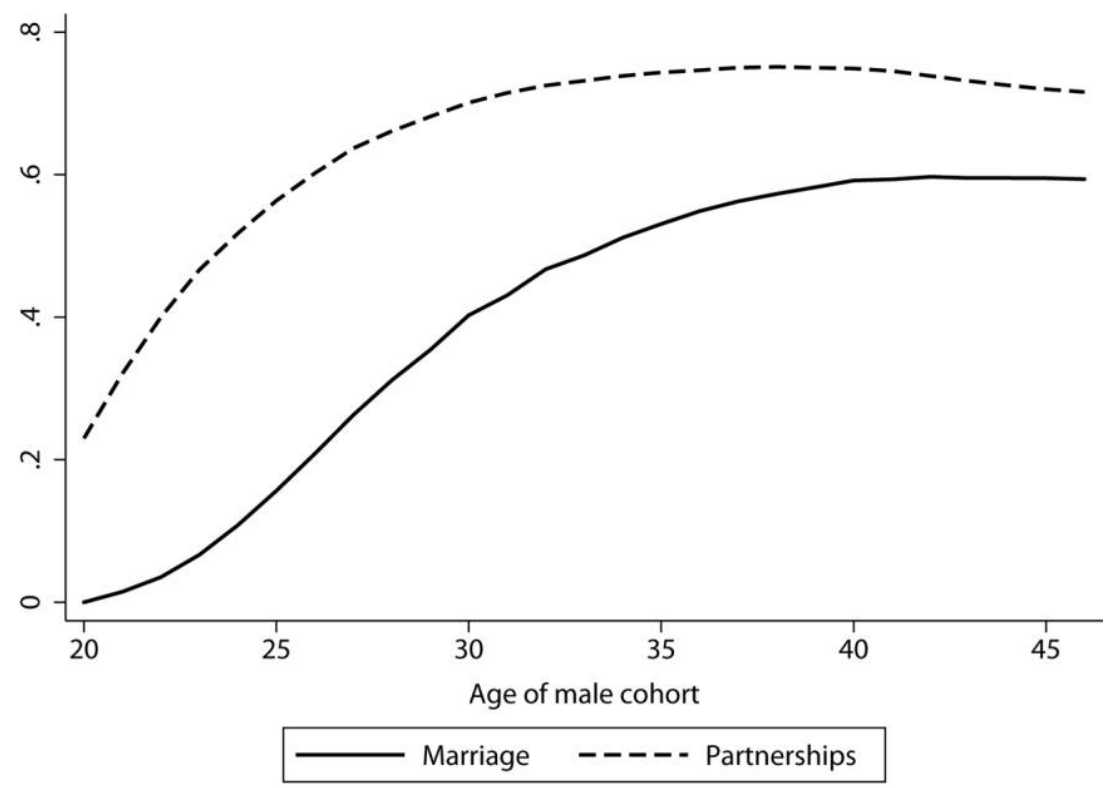

FIG. 1.-Fraction married or in partnerships (marriage plus cohabitation) by age. A color version of this figure is available online.

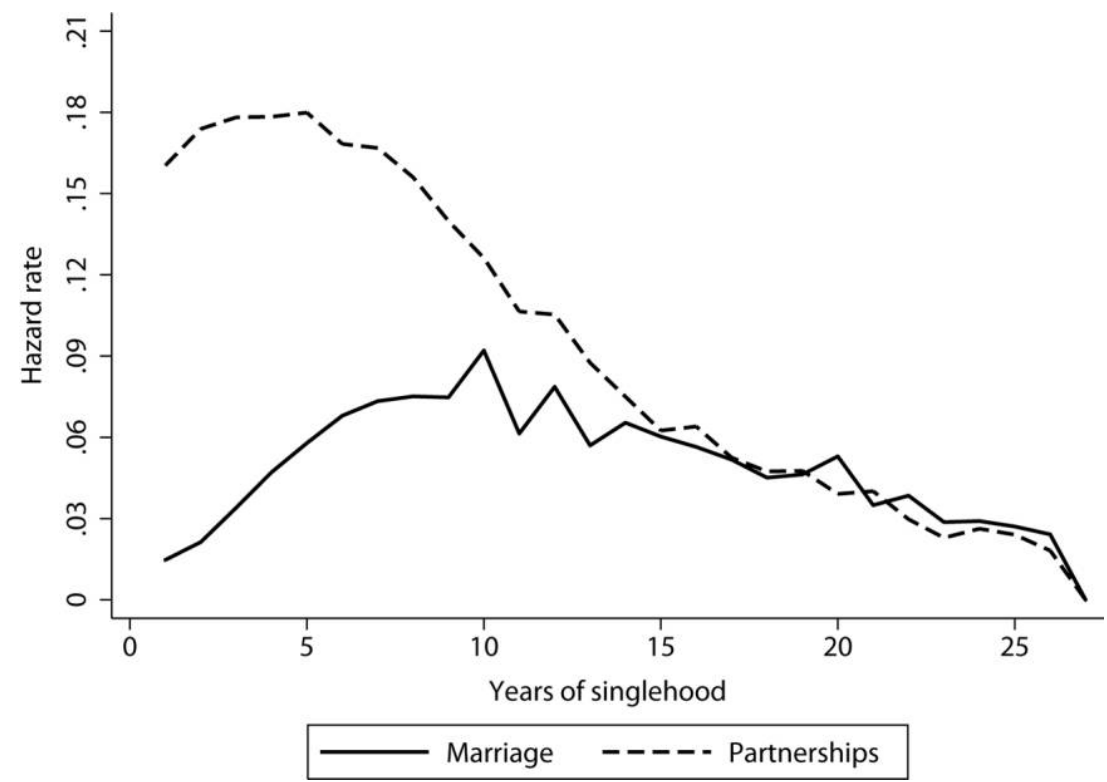

FIG. 2.- Hazard into first marriage or partnership (marriage plus cohabitation). A color version of this figure is available online. 


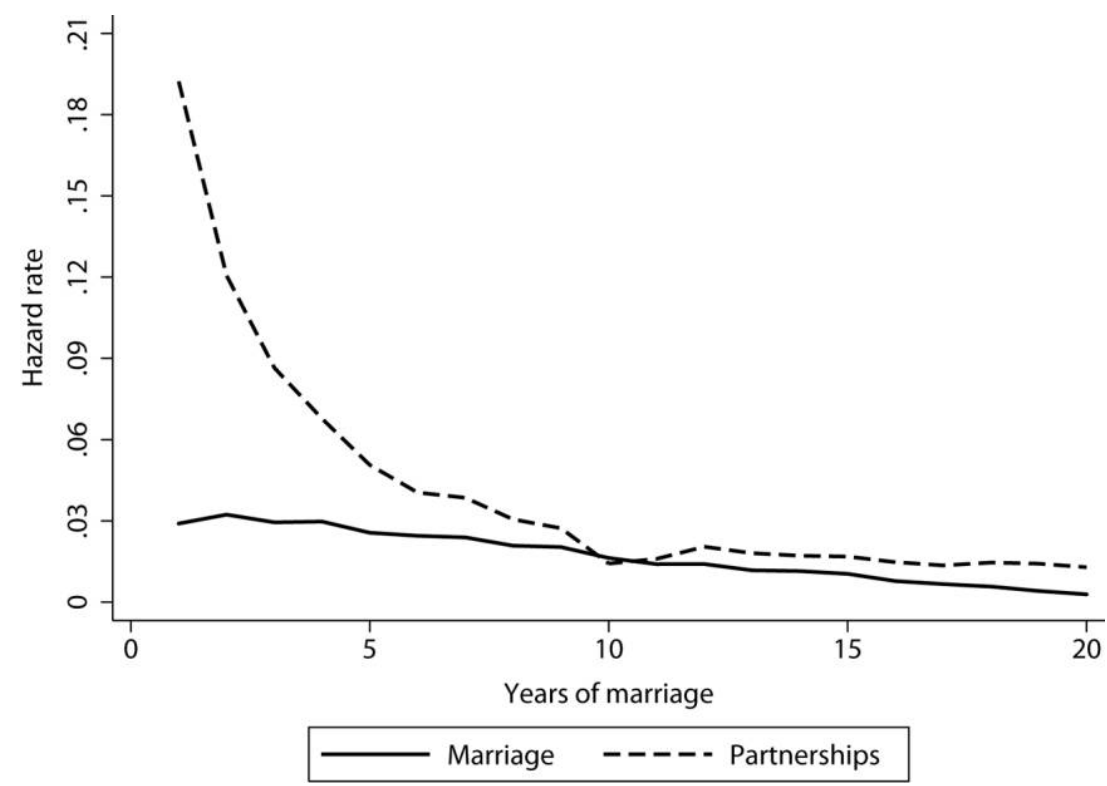

FIg. 3.-Divorce hazard for first marriage or partnership (marriage plus cohabitation). A color version of this figure is available online.

The figure shows that women with medium education have the highest rates of cohabitation at early ages and that men and women with high education delay their entry also into cohabitation. At the end of our sample, a substantial fraction of men and women at all levels of education are cohabiting without being married. Figure $4 C$ combines marriage and cohabitation and shows the fraction of men and women who are in a partnership by level of education. Most noticeably, men and women with high education have the highest rates of partnerships toward the end of our sample. Furthermore, men with low education are increasingly left behind, and at the end of our sample, 54\% of them are unmarried and $41 \%$ are without a partner.

\section{B. First Marriage}

The changes over time in the proportion of men and women who are married can be traced back to differences in the hazard to enter first marriage, to divorce, and to remarry. In figure 5, we show the hazard of entry into first marriage by education and gender. As one would expect, the hazard to enter first marriage is higher for women at early ages, and highly educated men and women delay their marriages. In figure 6, we show the divorce hazards for first marriage in different types of marriages as classified by the educations of the husband and the wife. The divorce hazards 


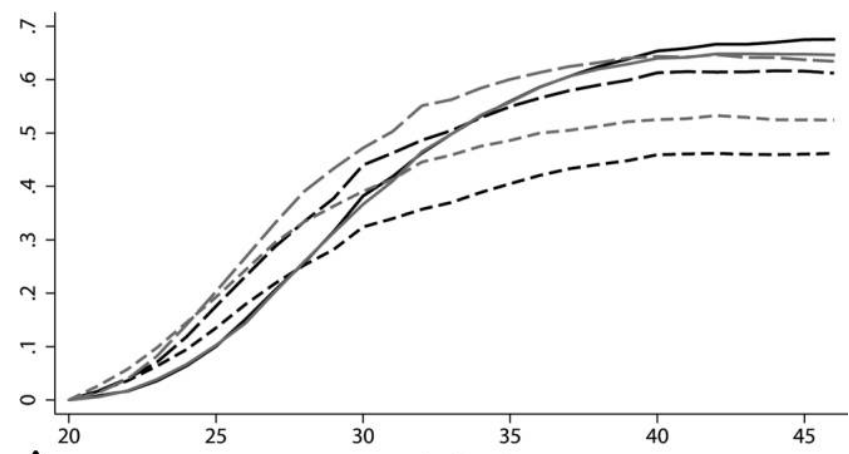

A

Age of male cohort

\begin{tabular}{|ll|}
\hline----- Men low & ----- Women low \\
--- Men medium & --- Women medium \\
\hline Men high & - Women high \\
\hline
\end{tabular}

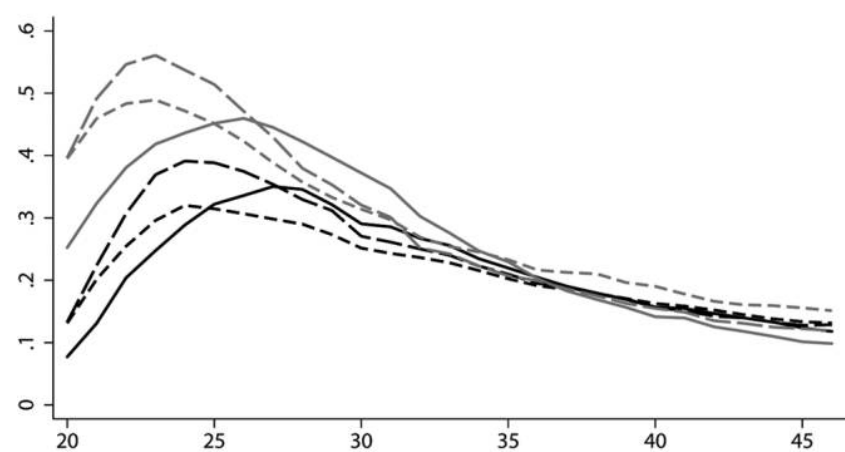

B Age of male cohort
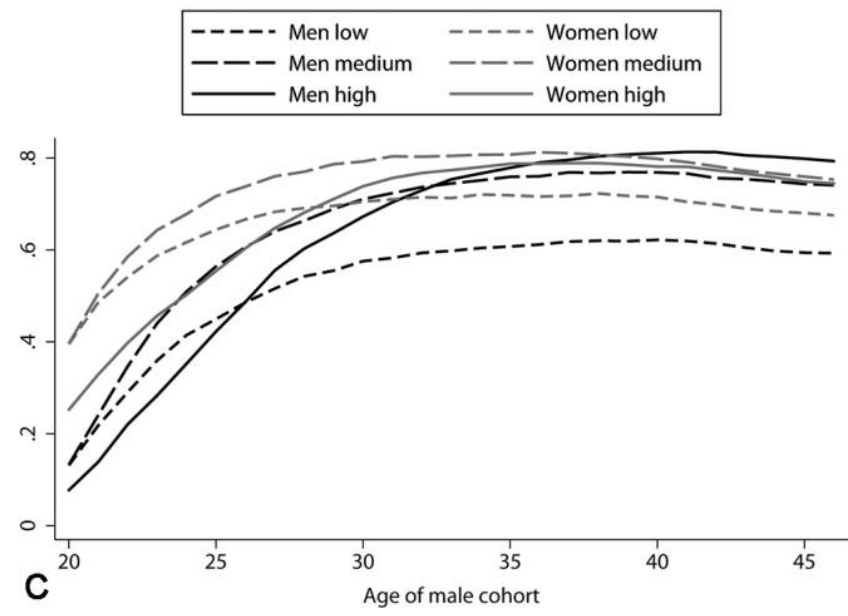

$\begin{array}{ll}----- \text { Men low } & ----- \text { Women low } \\ --- \text { Men medium } & --- \text { Women medium } \\ \text { Men high } & - \text { Women high }\end{array}$

FIG. 4.- $A$, Fraction married men and women by age and education; $B$, fraction cohabiting men and women by age and education; $C$, fraction men and women in partnerships by age and education. A color version of this figure is available online. 


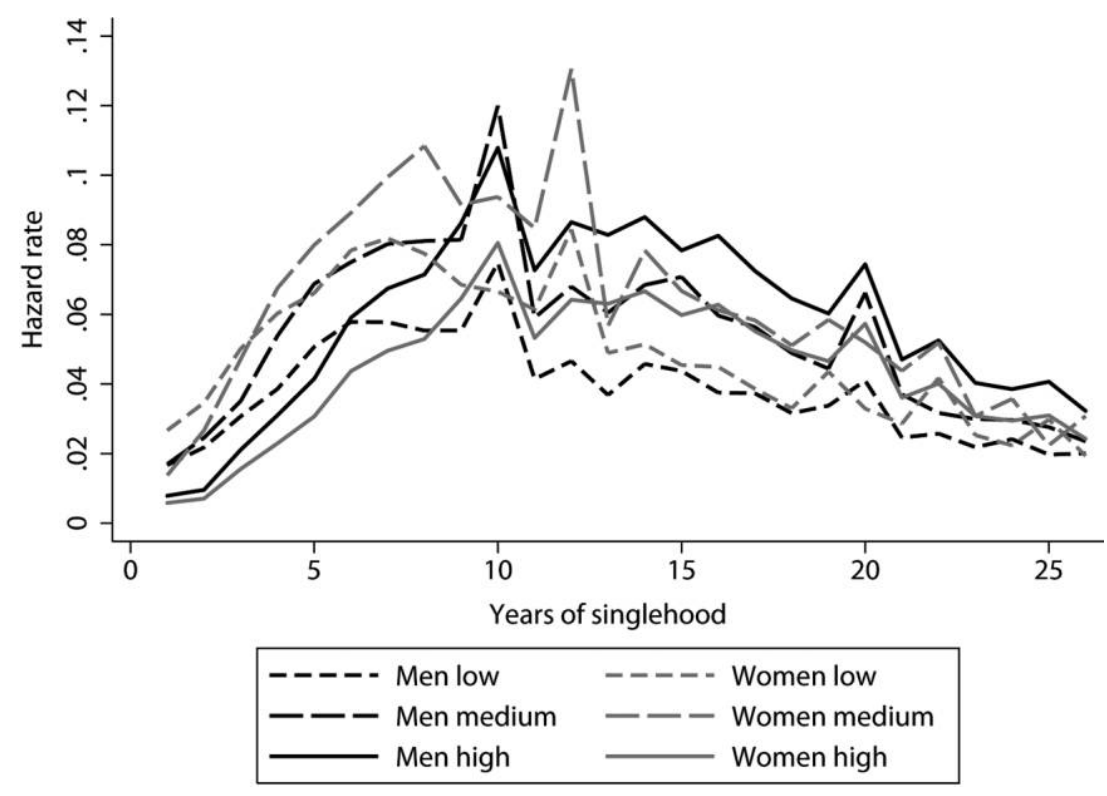

FIG. 5.- Hazard rate into first marriage for men and women by age and education. A color version of this figure is available online.
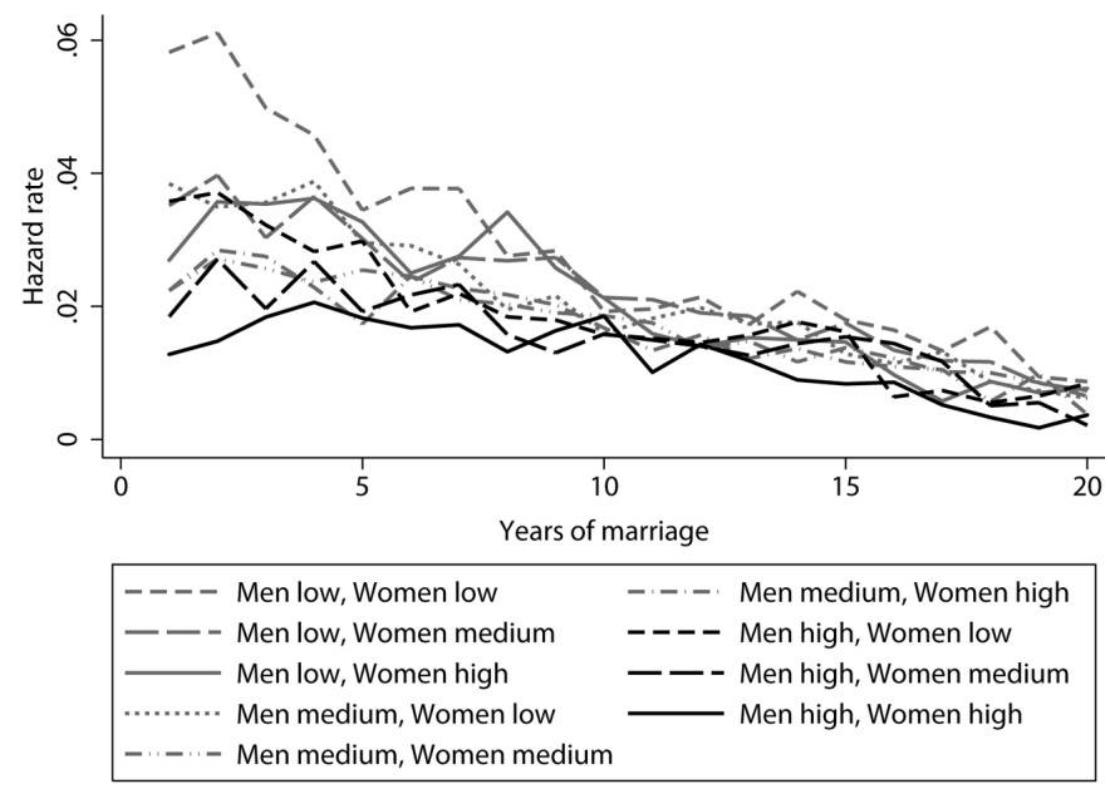

FIG. 6.-Divorce hazards for first marriages by education of the husband and wife. A color version of this figure is available online. 
are highest when both spouses have low education, and they are lowest when both spouses have high education.

\section{Second Marriage}

In figure 7, we show the hazards of entry into second and higher marriage by education and gender (henceforth, second and higher marriages will be denoted second marriages). The figure shows that individuals who divorce remarry quickly. Most noticeably, the hazards of entry into second marriage exceed the hazards of entry into first marriage (see also chap. 1 of Browning, Chiappori, and Weiss 2014). Men enter second marriages faster than women, and this is especially true for educated men. In figure 8, we show the divorce hazards for marriages in which at least one of the spouses has previously been divorced. The figure demonstrates that second marriages are substantially less stable than first marriages. This is especially the case if both spouses have low education. Similar results are reported by Svarer (2004) using Danish data and Parisi (2008) using British data.

D. Who Marries Whom

Figures 9 and 10 show the fraction of married men and women with different levels of education who are married to different types of partners as given by their educations. We see in the bottom of figure 9 that highly educated men marry mainly highly educated women. The proportion of

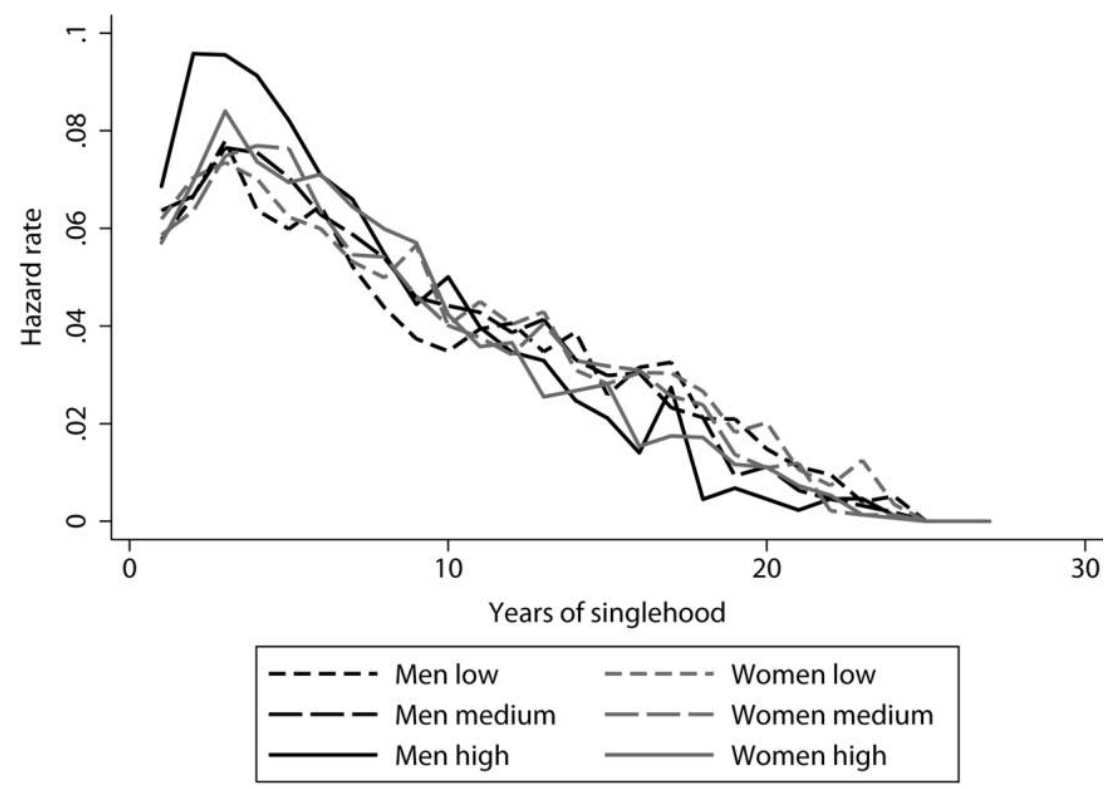

FIG. 7.-Hazard rate into second marriage for men and women by education. A color version of this figure is available online. 


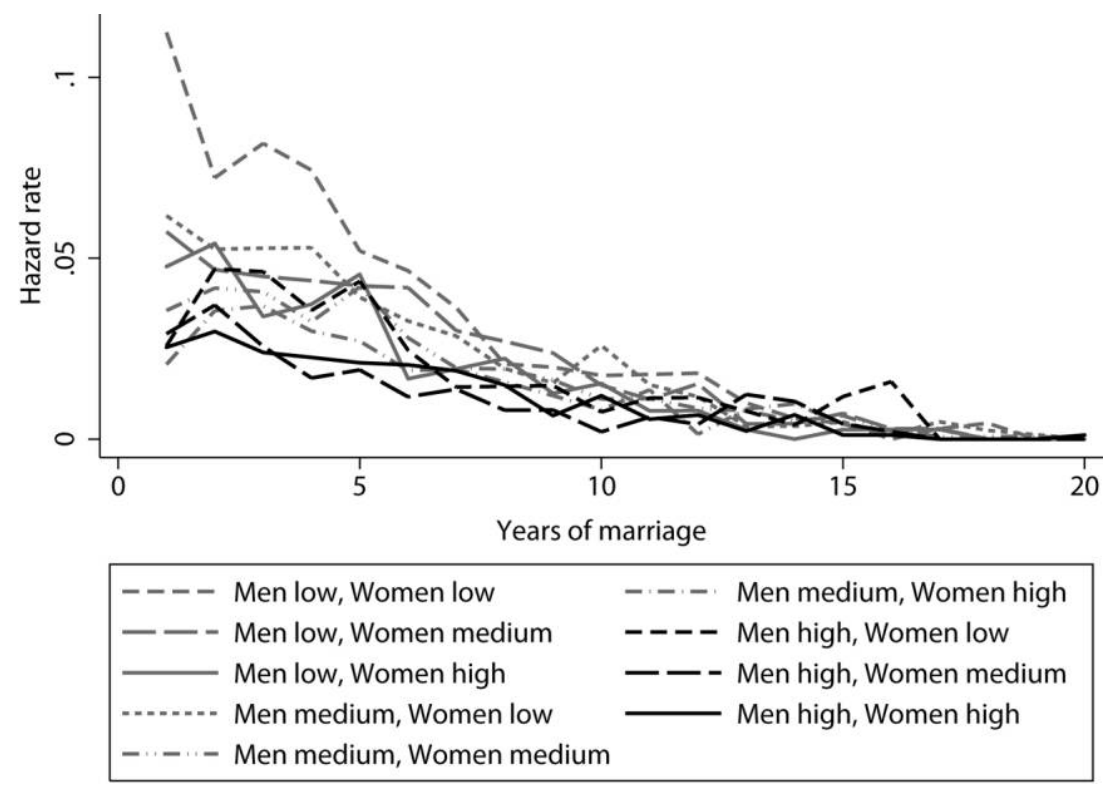

FIG. 8.-Divorce hazards when at least one spouse is in second marriage, by education of the husband and wife. A color version of this figure is available online.

married men with high education who are married to women with high education rises sharply as the cohorts get older, and it reaches $64 \%$ when the men are 46 years old. The probability that a married man with high education is married to a woman with high school or less declines sharply and reaches $12 \%$ when the men are 46 years old. About half of the married men with vocational education are married to women with vocational education, and this proportion remains stable as the cohort ages. Men with low education marry mainly women with low education. As the cohorts get older, the proportion of married men with low education who are married to women with high education rises, reflecting the higher stability of these marriages.

The marital choices of women are similar to those of the men, with some noticeable differences. In the bottom of figure 10, we see that the proportion of married women with high education who are married to men with high education reaches $52 \%$ when the women are 44 years old. This proportion is lower than the proportion of married men with high education who are married to women with high education. Furthermore, the proportion of married women with high education who are married to men with low education is $16 \%$ when the women are 44 years old. This proportion is higher then the proportion of men with high education who are married to women with low education. These two differences reflect 

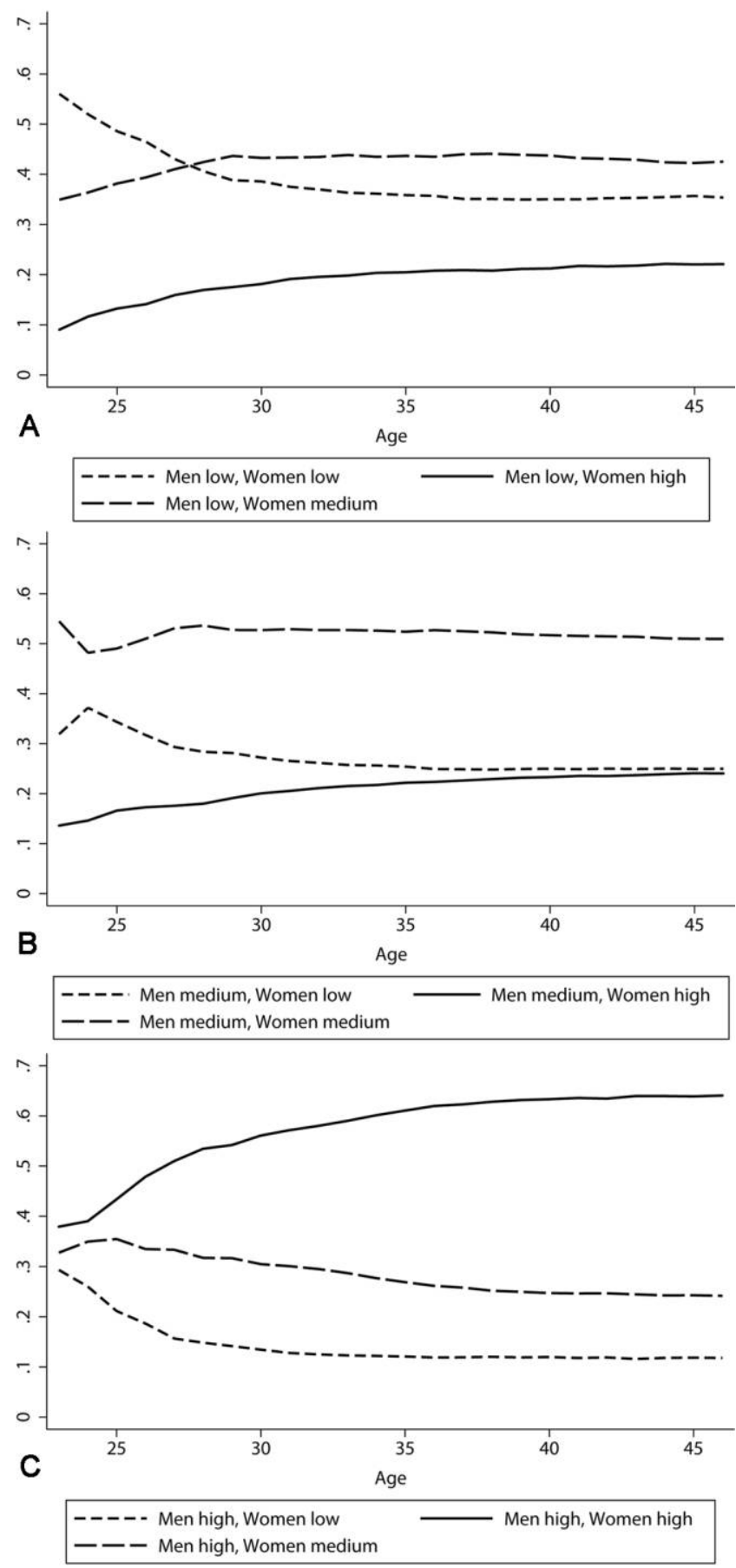

FIG. 9.-Distribution of marriages for men with low (top), medium (middle), or high (bottom) education. A color version of this figure is available online. 

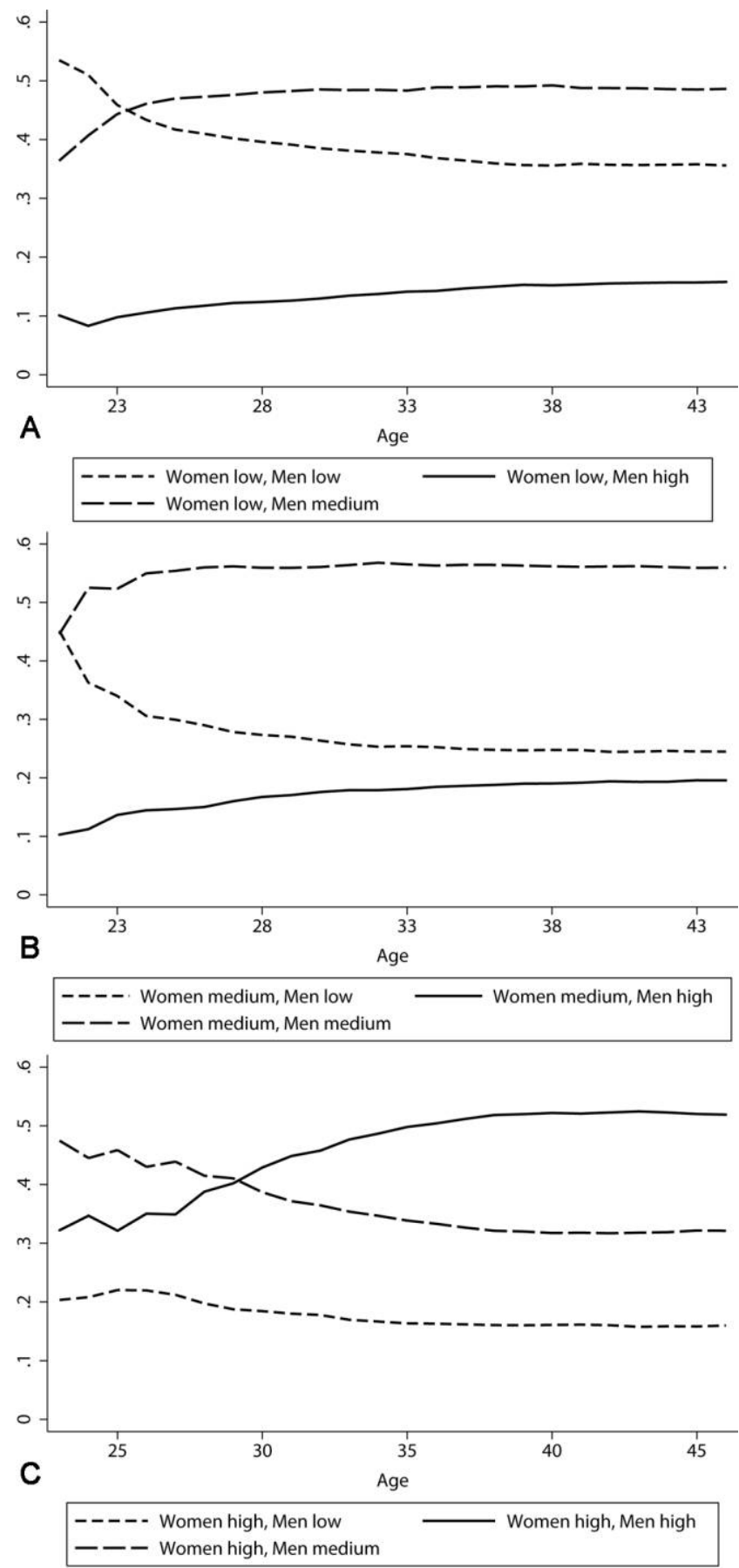

FIG. 10.-Distribution of marriages for women with low (top), medium (middle), or high (bottom) education. A color version of this figure is available online. 
the fact that women in our sample are more educated than men and are therefore forced to marry a husband with less education.

The choices of spouse are similar when we replace marriages by partnerships (i.e., marriage or cohabitation). For instance, the proportion of highly educated men in a partnership who have a spouse who is also highly educated is $64 \%$. The corresponding proportion for educated women is $52 \%$. The marital choices over time of men and women with different levels of education are also similar across first and second marriages. This is especially true after age 30 . $^{7}$

\section{E. Sorting in the Marriage Market}

As members of the male and female cohort get older and make new marriage and divorce decisions, the composition of single agents and married couples by their levels of education changes. These compositional changes also affect the degree of sorting over time. First of all, marriages in which both partners are highly educated are the most stable, and, as a result, the proportion of these marriages rises over time. Second, men and women with low education are more likely to remain single after a divorce, and, as a result, marriages involving men and women with low education become increasingly rare. This trend is noticeably stronger among men. By age $46,40 \%$ of the unmarried men have low education, whereas only $18 \%$ have high education. The corresponding percentages among women by age 44 are $33 \%$ and $29 \%$, respectively. The role of education in stabilizing marriages and the difficulties that less educated men face in marriage are not unique to Denmark. Similar results for the United States are reported by Weiss and Willis (1997), Stevenson and Wolfers (2007), Isen and Stevenson (2010), and Martin (2012).

\section{A Dynamic Model of Marriage and Divorce}

\section{A. The General Approach}

We now propose a dynamic model that captures and interprets the main features observed in our data. The general approach is matching with transferable utility and without frictions. The key simplifying assumption is that men and women can be classified into a small number of types. Every man and woman is indifferent between all potential partners of the same type but still has idiosyncratic preferences over different types. Given the large number of men and women of each type, it follows that all members of a given type receive the same share of the marital surplus in a given type of marriage. When making their marital decisions, men and women are forwardlooking and have perfect foresight of the surplus shares that married men

${ }^{7}$ One exception is that the proportion of marriages in which both partners have medium education is higher in first marriages. 
and women receive throughout their lifetime. In this framework, we analyze individual choices to marry, divorce, and remarry, and we aggregate outcomes such as the number of men and women who remain single and the types of marriages that are formed and survive.

\section{B. Types of Men and Women}

Time is discrete, and the economy is populated by men and women, who can choose to be single or to marry a member of the opposite sex. All men and women live for $T$ periods, die, and then receive no further utility. Utility flows in these $T$ time periods are discounted geometrically with the discount factor $R$. We denote the time period by $t$.

Men and women are characterized by their educational attainment $e$, which can be either low, medium, or high. We denote the set of these three educational types by $E=\{l, m, h\}$. Men and women are also characterized by their marital histories $p_{t}$. We distinguish between men and women who have never been married $\left(p_{t}=n m\right)$ and men and women who have been married previously $\left(p_{t}=p m\right)$. The set of these two types is denoted by $P_{t}=$ $\{n m, p m\}$. Finally, men and women are characterized by their preferences for being single, which are observed by all agents in the model but not by the econometrician. These preference types are intended to capture the permanent unobserved differences in the willingness to marry. We let $U=\{1,2\}$ denote the set of these two preference types.

In total there are thus 12 types of men, which we index by the letter $I \in$ $E \times P_{t} \times U, 12$ types of women, which we index by the letter $J \in E \times P_{t} \times$ $U$, and a total of 144 different types of marriages, as given by all possible combinations of husband and wife types $I J$.

\section{Marriage}

If married, a man of type $I$ and a woman of type $J$ generate together a marital output flow that they can divide between them. We assume that the systematic component of the marital output flow, denoted by $\xi^{I J}$, depends on the educations and the marital histories of both partners but not on their preference types or ages (although age has an indirect effect on utility via the marital histories of the partners). We allow for full interactions in the educations of the husband and the wife so that we can test for the complementarity of male and female education. In addition, the order of marriage enters in a separable additive manner, which allows us to rank marriages by their order. Specifically, the systematic part of the marital output flow in a given $I J$-marriage is

$$
\zeta^{I J}=\Sigma_{I} \Sigma_{J} \alpha^{I J} e^{I J}+\sum_{I} \Sigma_{J} \beta^{I J} p^{I J}
$$

where $e^{I J}$ is a dummy variable that takes on a different value for each of the nine possible combinations of husband and wife education and $p^{I J}$ is a dummy variable that takes on a different value for each of the four com- 
binations of husband and wife marital histories. By assumption, the marital output flow is constant over time in given marriage $I J$. We assume that upon dividing the marital output, utility is transferred between the husband and the wife at a one-to-one exchange rate.

In addition to the systematic part $\zeta^{I J}$, partners receive a flow utility from the quality of their match $\theta_{t}{ }^{8}$. The quality of match is an independent and identically distributed (iid) match-specific random variable drawn from a standard normal distribution, which is revealed to the partners only at the end of each period. In this regard, marriage is an "experience good." In particular, single agents who marry at time $t$ do not know the quality of their match $\theta_{t}$ and expect it to equal the mean, which is set to zero.'

Following the realization of their match quality, the partners decide whether to continue the marriage or not. Since utility is transferable in marriage, the decision to divorce depends only on the sums of the utilities of the husband and the wife after a separation. Hence, husbands and wives "agree" on when to divorce (Becker et al. 1977). The total utility flow of partners who stay married is $\zeta^{I J}+\theta_{t}$. By divorcing, the partners can avoid a bad realization of their match-specific quality. However, divorce also entails a fixed cost of separation $s_{t}$, which depends on the duration of the marriage, $d_{t}$, up to the time of divorce, through the function $s_{t}=s\left(d_{t}\right)$. This divorce cost plays an important role in the model since it reduces "experimental short marriages" and limits turnover.

\section{Singlehood}

Single men and women receive a flow utility of $\varphi_{t}^{I}$ and $\varphi_{t}^{J}$ each period. This flow utility includes a systematic part, $\mu_{t}^{I}$ for men and $\mu_{t}^{J}$ for women, which depends on their ages and educations, and an idiosyncratic part, $u^{I}$ for men and $u^{J}$ for women, which represents the individual preferences to be single and is assumed to be constant over time. The idiosyncratic term can take two values for single men, $u_{1}{ }^{I}$ and ${u_{2}}^{I}$, and two values for single women, $u_{1}^{J}$ and $u_{2}^{J}$.

The total flow utility of being single for a man of type $I$ in year $t$ is

$$
\begin{aligned}
& \varphi_{t}^{I}=\mu_{t}^{I}+u_{1}^{I} \text { if preference Type } 1, \\
& \varphi_{t}^{I}=\mu_{t}^{I}+u_{2}^{I} \text { if preference Type } 2,
\end{aligned}
$$

${ }^{8}$ This specification is borrowed from Browning et al. (2014, chap. 6). Partners may have different evaluations of the marriage, $\theta^{a}$ and $\theta^{b}$. We denote the sum of these evaluations by $\theta$. Only the sum matters as long as partners can transfer resources to compensate each other for differences in $\theta$. This is always feasible if the evaluations do not differ much. To simplify, we assume here that this is the case.

${ }^{9}$ For a more general treatment of learning on match quality, see Brien et al. (2006). 
and the total flow utility of being single for a woman of type $J$ in year $t$ is

$$
\begin{aligned}
& \varphi_{t}^{J}=\mu_{t}^{J}+u_{1}^{J} \text { if preference Type } 1, \\
& \varphi_{t}^{J}=\mu_{t}^{J}+u_{2}^{J} \text { if preference Type } 2 .
\end{aligned}
$$

Because we deal with a model of discrete choice, some normalizations are required. In a static model, it is customary to normalize the flow value from being single to zero for both men and women. However, in a multiperiod model, the value of marriage relative to singlehood can vary over time and by schooling and gender. At ages above 40 for men and above 38 for women, we set the systematic components $\mu_{t}^{I}$ and $\mu_{t}^{J}$ equal to zero. For lower ages, we allow the systematic utility components to depend on the gender, age, and education of the single agents. We also normalize the idiosyncratic utility flow of Type 1 agents $u_{1}^{I}$ and $u_{1}^{J}$ to zero in all periods.

A divorced person must remain single for a whole period. At the end of every time period $t$, single agents receive iid shocks to their preferences over remaining single or entering a marriage in period $t+1$ with a husband of type $I$ or a wife of type $J$, where $I \in E \times P_{t} \times U$, and $J \in E \times P_{t} \times U$. We denote these shocks by $\varepsilon_{t+1}^{0}, \varepsilon_{t+1}^{I}$, and $\varepsilon_{t+1}^{J}$, respectively, and we assume that they are drawn from a standard extreme value distribution. These random variables represent unobserved transitory taste considerations (or optimization and classification errors). These taste shocks allow observationally identical individuals to make different choices with regard to remaining single or marrying a particular type of spouse at time $t$. We assume that preference shocks revealed at the end of the time period $t$, prior to the decision of single agents to remain single or marry, have no impact on the utility flows from marriage or singlehood in subsequent periods beyond $t+1$.

Since the shocks to the preferences of single agents are related to the types of spouse whom they marry and not to individual agents, single men and women are indifferent between marrying different agents of the same type. As a consequence, in equilibrium, these agents must receive the same share of the expected marital surplus in a given type of marriage. We formalize this property by letting $\gamma_{t}^{I J}$ be the share of the systematic marital surplus that is obtained by a man of type $I$ who marries a woman of type $J$ in time period $t$ (the woman of type $J$ receives the share $1-\gamma_{t}^{I J}$ ). We emphasize that these parameters reflect the share from the systematic surplus of the marriage as expected at the time of marriage.

\section{E. Bellman Equations}

With this characterization of the economic environment, we can introduce the Bellman equation for the value of marriage. For that purpose, let $W_{t}^{I J}\left(d_{t}\right)$ be the total expected value of an ongoing marriage between a 
man of type $I$ and a woman of type $J$ at time $t$, which has lasted for $d_{t}$ years, prior to the realization of the match quality $\theta_{t}$. The value of the marriage after the shock is revealed is $W_{t}^{I J}\left(d_{t}\right)+\theta_{t}$, and it satisfies the Bellman equation

$$
\begin{aligned}
W_{t}^{I J}\left(d_{t}\right)+\theta_{t}= & \zeta^{I J}+\theta_{t} \\
& +R E_{t}\left[\max \left\{W_{t+1}^{I J}\left(d_{t+1}\right)+\theta_{t+1}, V_{t+1}^{I}+V_{t+1}^{J}-s\left(d_{t+1}\right)\right\}\right] .
\end{aligned}
$$

Equation (4) states that the total value of marriage plus the realized match quality equals the sum of the systematic marital output flow $\xi^{I J}$ and the match quality $\theta_{t}$ in the current period $t$ plus the discounted expected value of the marriage in the next period. The expectation is taken over the maximum of the two options that are available to the couple in the next period: remain married or divorce. If the couple remains married, they receive a utility flow equal to the total value of the marriage in the next period $W_{t+1}^{I J}\left(d_{t+1}\right)$ plus the subsequent realization of the match quality $\theta_{t+1}$. If the couple decides to divorce, each partner receives his/her expected utility as single in the next period net of his/her share of the divorce costs $s\left(d_{t+1}\right)$. Because utility is transferable both within marriage and after divorce, divorce does not depend on the surplus shares that the partners receive within marriage nor does it depend on the division of the cost of separation, $s\left(d_{t+1}\right.$ (see Chiappori, Iyigun, and Weiss 2007).

The Bellman equation for marriage prior to the realization of the match quality is

$$
W_{t}^{I J}\left(d_{t}\right)=\xi^{I J}+R E_{t}\left[\max \left\{W_{t+1}^{I J}\left(d_{t+1}\right)+\theta_{t+1}, V_{t+1}^{I}+V_{t+1}^{J}-s\left(d_{t+1}\right)\right\}\right] .
$$

Note that (5) is obtained from (4) by eliminating the match quality shock $\theta_{t}$, which appears both on the left- and the right-hand sides of the equality sign in (4).

In a similar fashion, we can specify the Bellman equation for the value of singlehood. For that purpose, let $V_{t}^{I}$ be the expected value of being single for a man of type $I$ at time period $t$, prior to the realization of the preference shocks $\varepsilon_{t+1}$, which are observed at the end of period $t$ but only affect the utility of the agent in the next time period $t+1$. The value $V_{t}^{I}$ then satisfies the Bellman equation

$$
V_{t}^{I}=\varphi_{t}^{I}+R E_{t}\left[V_{t+1}^{I}+\max _{J \in E \times P_{t} \times U}\left\{\varepsilon_{t+1}^{0}, \gamma_{t+1}^{I J}\left[W_{t+1}^{I J}(1)-V_{t+1}^{I}-V_{t+1}^{J}\right]+\varepsilon_{t+1}^{J}\right\}\right]
$$

Equation (6) states that the value of being single in time period $t$ is the flow value of being single in the current period $\varphi_{t}^{I}$ plus the discounted 
expected value of being single in the next period. The discounted expected value of being single in period $t+1$ is the expectation of the maximum over the options available to a single man: remain single or marry a woman of a given type $J \in E \times P_{t} \times U$. If the man chooses to remain single, he receives a utility equal to the value of being single in the next time period plus the realization of the preference shock. If the man decides to marry, he receives a utility equal to the value of being single, plus his share of the marital surplus in the particular type of marriage, plus the realization of the preference shock. Finally, the value $V_{t}^{J}$ of being single for a woman of type $J$ at time $t$ satisfies the Bellman equation

$$
V_{t}^{J}=\varphi_{t}^{J}+R E_{t}\left[V_{t+1}^{J}+\max _{I \in E \times P_{t} \times U}\left\{\varepsilon_{t+1}^{0},\left(1-\gamma_{t+1}^{I J}\right)\left[W_{t+1}^{I J}(1)-V_{t+1}^{I}-V_{t+1}^{J}\right]+\varepsilon_{t+1}^{I}\right\}\right]
$$

Our assumptions on the distributions of the shocks allow us to solve the Bellman equations analytically, following the procedures discussed by Rust (1994).

As is clear from the equations above, we view marriage as a risky investment that has an asset value that can be divided between partners. The systematic marital surplus that depends only on the type of marriage is $W_{t+1}^{I J}(1)-V_{t+1}^{I}-V_{t+1}^{J}$. Individuals with a high draw of $\varepsilon$ may enter a marriage even if the systematic marital surplus is negative, provided that $\varepsilon_{t}+1$ is sufficiently high.

\section{Commitment}

As we noted above, the surplus shares of husbands and wives do not depend on the idiosyncratic preferences for marriage $\varepsilon$ of individual agents as men and women are indifferent between all spouses of a given type and will not pay their prospective spouse more than the "going price."10 However, the costs of divorce generate ex post rents and bargaining. We assume that partners commit at the time of marriage to the shares within marriage, with an option to renegotiate if the match quality or the number of available singles change. Given this flexibility, divorce is efficient under transferable utility. As researchers, we cannot observe revisions in the shares within a given marriage, but we assume that the agents fully anticipate these revisions at the time of marriage when $\gamma$ is formed. Indeed, we assume perfect foresight of all agents regarding all future variables that

${ }^{10}$ Recall that by assumption the unobserved preferences for singlehood are observed by all agents and all shocks are iid. Hence, conditioned on schooling and preference types, individuals with the same marital history are treated equally and receive the same surplus share. 
can affect their current choices. Based on observed choices, we can then estimate the surplus shares that agents expect at the time of marriage. ${ }^{11}$

\section{Stability Conditions}

The Bellman equations impose two important constraints on the data. First of all, each marriage that forms must be the best choice for both of the spouses given the expected surplus from the marriage, its division between the spouses as expected at the time of marriage, and their idiosyncratic preferences $\varepsilon$ at the time of marriage. Second, if a marriage does not end in divorce, both spouses must wish to remain married as the sum of the expected systematic gains from continuing the marriage and the realized match quality exceeds the sum of their expected values of singlehood minus the cost of separation.

However, we do not impose in our model that the number of single men who enter into marriage every year has to equal the number of single women who enter into marriage. This means that our model differs from a fully specified general equilibrium model and can best be described as an approximation of the market clearing mechanism in the marriage market.

\section{Estimation}

\section{A. Econometric Specification}

In the econometric specification of the shares of the systematic marital surplus, one could in principle maintain a different share for each type of marriage in each time period. But such a specification would involve too many parameters to be estimated. ${ }^{12}$ Instead, we model the systematic surplus shares parametrically as a function of husband and wife education, husband and wife marital histories, and time (age). Specifically, we use a quadratic function of time, $\rho^{I J}+\kappa^{I J} t+\lambda^{I J} t^{2}$, which is then embedded in the ratio of two exponential functions to ensure that each systematic share takes on a value between zero and one:

$$
\gamma_{t}^{I J}=\frac{\exp \left\{\rho^{I J}+\kappa^{I J} t+\lambda^{I J} t^{2}\right\}}{1+\exp \left\{\rho^{I J}+\kappa^{I J} t+\lambda^{I J} t^{2}\right\}} .
$$

We show below that this formulation, which has only 108 parameters, is flexible enough to capture the observed relative entry rates into marriage of different types of single men and women.

To parameterize the fixed cost of divorce as a function of the duration of marriage, we introduce 10 different dummy parameters correspond-

${ }^{11}$ Mazzuco et al. (2007) use data on consumption and labor supply to infer the changes in shares during marriage.

${ }^{12}$ Specifying one parameter for each surplus share in every type of marriage would result in a model with in the order of 7,000 parameters. 
ing to the costs of divorce after $1,2,3, \ldots, 10$ or more years of marital duration $d_{t}$.

\section{B. Likelihood Function}

We estimate the structural model through maximum likelihood, using the full set of marital transitions from 1980 to 2006 for each of the 62,431 individuals in our sample. We take the initial state of all men and women in 1980 as given and maximize a conditional likelihood function. Due to the way we have constructed our sample, this means that all men and women start out as singles with no previous marriages.

To construct the theoretical transition probabilities, we assume that all men and women live to the age of 71 . We then compute the value of being single and the total value of marriage recursively back to the initial observation year. The discount factor is set to $R=(1 / 1.03)$.

In a given year, an agent of a particular gender, education, and preference type can find himself or herself in a total of 242 states. A first state is defined as being single with no previous marriage, and a second state is defined as being single with one or more previous marriages. The additional 240 states are marriages characterized by the marital history of the agent, the marital history of the spouse, the education and preference type of the spouse, and the duration of the marriage.

To describe the conditional likelihood function, we index male individuals by $i=1,2, \ldots, N^{m}$; female individuals by $j=1,2, \ldots, N^{f}$; and time periods by $t=1,2, \ldots, T$. Let $O_{i t}$ be the observed outcome of male $i$ at time $t$, and let $O_{j t}$ be the observed outcome of female $j$ at time $t$. Assuming independence between individuals, the conditional likelihood $L$ of observing our sample given the initial states of all men $S_{i 0}$ and women $S_{j 0}$, is

$$
\begin{gathered}
L=\prod_{i} \operatorname{Pr}\left(O_{i 1}, \ldots, O_{i T} \mid S_{i 0}\right) \prod_{j} \operatorname{Pr}\left(O_{j 1}, \ldots, O_{j T} \mid S_{j 0}\right)= \\
\prod_{i}\left[q_{1}^{m} \operatorname{Pr}\left(O_{i 1}, \ldots, O_{i T} \mid S_{i 0}, u=1\right)+\left(1-q_{1}^{m}\right) \operatorname{Pr}\left(O_{i 1}, \ldots, O_{i T} \mid S_{i 0}, u=2\right)\right] \times \\
\prod_{j}\left[q_{1}^{f} \operatorname{Pr}\left(O_{j 1}, \ldots, O_{j T} \mid S_{j 0}, u=1\right)+\left(1-q_{1}^{f}\right) \operatorname{Pr}\left(O_{j 1}, \ldots, O_{j T} \mid S_{j 0}, u=2\right)\right],
\end{gathered}
$$

where $q_{1}^{m}$ is the fraction of Type 1 agents among men, $q_{i}^{f}$ is the fraction of Type 1 agents among women, and $u \in\{1,2\}$ is an index for the two unobserved preference types.

When calculating the transition probabilities over observed states, we take into account selection on unobservables. In particular, we update the type probabilities of married partners based on the duration of marriage. 
To maximize the conditional log-likelihood function, we use a simplex optimization algorithm. The standard errors of the parameter estimates are then computed using the outer product of the scores of the conditional loglikelihood function.

The model that we estimate assumes that all divorced men and women have to be single for at least 1 year before they can remarry. In the data, we observe a few cases (less than $1 \%$ of the total number of observations) for which men and women move directly from one marriage to another without being recorded as single in between. For these few cases, we assume that the first year of the new marriage is singlehood.

\section{Identification}

We start our discussion of identification by considering the case in which there is no unobserved heterogeneity. The parameters of the structural model are then related to closed form expressions of the observed divorce and marriage probabilities in the data.

The assumption of transferable utility in marriage implies that divorce probabilities are only a function of the systematic marital surplus in each type of marriage and the costs of divorce. The observed divorce probabilities of different types of marriage at different durations of marriage therefore identify the size of the systematic marital surplus minus the costs of divorce. Specifically, it is seen from Bellman equation (5) that

$$
V_{t}^{I}+V_{t}^{J}-s\left(d_{t}\right)-W_{t}^{I J}=\Phi^{-1}(\text { prob of divorce in year } t),
$$

where $\Phi$ is the standard cumulative normal distribution function.

The multinomial extreme value structure of the preference shocks to single agents (see eqq. [6] and [7]) implies that the observed ratio of choice probabilities for single agents identifies the difference in utility between any two marital choices (see McFadden 1984). For example, the difference in utility for a single man of type $I$ in year $t$ between marrying a wife of type $J$ or remaining single can be expressed as

$$
\begin{aligned}
& V_{t}^{I}+\gamma_{t}^{I J}\left[W_{t}^{I J}(1)-V_{t}^{I}-V_{t}^{J}\right]-V_{t}^{I}=\gamma_{t}^{I J}\left[W_{t}^{I J}(1)-V_{t}^{I}-V_{t}^{J}\right] \\
& =\ln \left(\frac{\operatorname{Pr}(\text { single man of type } I \text { selects a wife of type } J \text { in year } t)}{\operatorname{Pr}(\text { single man of type } I \text { remains single in year } t)}\right) .
\end{aligned}
$$

Thus, the marital choices of single men identify the systematic marital surplus

$$
\gamma_{t}^{I J}\left[W_{t}^{I J}(1)-V_{t}^{I}-V_{t}^{J}\right]
$$

that men receive in different types of marriages. In an analogous way, the marital choices of single women identify the systematic marital surplus 


$$
\left(1-\gamma_{t}^{I J}\right)\left[W_{t}^{I J}(1)-V_{t}^{I}-V_{t}^{J}\right]
$$

that women receive in different types of marriages.

Furthermore, the ratio of choice probabilities for different types of single agents can be combined to identify the systematic marital surplus shares of husbands $\gamma_{t}^{I J}$ and of wives $\left(1-\gamma_{t}^{I J}\right)$ in each type of marriage. This can be seen by noting that

$$
\begin{gathered}
\frac{\gamma_{t}^{I J}}{1-\gamma_{t}^{I J}}=\frac{\gamma_{t}^{I J}\left[W_{t}^{I J}(1)-V_{t}^{I}-V_{t}^{J}\right]}{\left(1-\gamma_{t}^{I J}\right)\left[W_{t}^{I J}(1)-V_{t}^{I}-V_{t}^{J}\right]}= \\
=\frac{\ln \left(\frac{\operatorname{Pr}(\text { single man of type } I \text { selects a wife of type } J \text { in year } t)}{\operatorname{Pr}(\text { single man of type } I \text { remains single in year } t)}\right)}{\ln \left(\frac{\operatorname{Pr}(\text { single woman of type } J \text { selects a husband of type } I \text { in year } t)}{\operatorname{Pr}(\text { single woman of type } J \text { remains single in year } t)}\right)} .
\end{gathered}
$$

In words, the systematic marital surplus shares $\gamma_{t}^{I J}$ are identified from the willingness of single men of type $I$ to enter into a $I J$-marriage at time $t$ relative to the willingness of single women of type $J$ to enter into the same kind of marriage.

It is also useful to notice that data on the inflows to marriage identify both the systematic marital surplus received by men and women (see eqq. [10] and [11]) and the systematic marital surplus shares $\gamma_{t}^{I J}$. Combining these quantities, it is clear that data on the marital choices of all single agents also identify the systematic surplus $W_{t}^{I J}(1)-V_{t}^{I}-V_{t}^{J}$ in each type of marriage.

Since data on the inflows to marriage by single agents identify the systematic surplus $W_{t}^{I J}(1)-V_{t}^{I}-V_{t}^{J}$ in each type of marriage and data on divorce probabilities identify the systematic marital surplus minus the cost of divorce $V_{t}^{I}+V_{t}^{J}-s\left(d_{t}\right)-W_{t}^{I J}$, the combination of data on inflows to marriage and divorce probabilities identify the cost of divorce $s\left(d_{t}\right)$. This argument applies to the cost of divorce for a marriage that has lasted for 1 year. Since the only difference in the structural model between marriages of different durations is the cost of divorce, data on the relative divorce probabilities of marriages with different durations identify the costs of divorce also for these longer marriages.

The arguments above show that only the systematic martial surplus at different points in time is identified but not the absolute levels of utility in singlehood or in marriage. Thus, we cannot separately identify the flow utility for singles in each period and the flow utility in marriage in each period. We therefore make two normalizations that are necessary to estimate the parameters of the model. First of all, we assume that the flow utility in marriage is constant over time. Second, we normalize the flow utility in 
singlehood so that it equals zero for men above age 40 and women above age 38. It is important to note that all the estimated parameters of the flow utility in marriage and in singlehood need to be interpreted relative to this normalization. With these two different normalizations, it is then possible to recover the parameters that govern the flow utility in singlehood and in marriage through the structure of the Bellman equations (5), (6), and (7) together with the assumption that life ends at age 71 .

Without unobserved heterogeneity, the structural model is overidentified since we have more year-person marital transitions than what is necessary to identify the parameters governing the flow utility in marriage, singlehood, and the cost of divorce. The additional parameters that govern the unobserved utility of being single $u^{i}$ and $u^{j}$ and the shares in the sample of the two unobserved types $q_{1}^{m}$ and $q_{i}^{f}$ are identified from the changes in the hazards of entry into marriage and the divorce hazards over time. For example, the sharp drop in the hazards of entry into first and second marriages allows us to identify the heterogeneity among men and women in their willingness to enter marriage relative to remaining single. ${ }^{13}$

\section{Results}

We now present our estimation results. We first examine the overall fit of the model and then interpret the coefficients. We discuss the estimated marital output flow and the estimated costs of divorce. Finally, we present and discuss the estimated shares of the marital surplus received by husbands and wives. The detailed estimated coefficients and their standard errors are presented in the appendix.

\section{A. Quality of Fit}

The estimated model fits the marriage rate for women over the sample period well, but it slightly underpredicts the marriage rate for men (see fig. 11). For both men and women, the model fits the inflow to first marriage very well (see fig. 12). One exception is the sharp peaks in the hazards of entry into first marriage, which are observed at ages 30 and $40 .{ }^{14}$ The model also fits the divorce hazards for first and second marriages (see figs. 13 and 15), although it underestimates the differences in hazards between couples with different levels of education in the early years of the marriage. Finally, the model fits well the inflows to second marriage for both men and women (see fig. 14).

${ }^{13}$ However, we were unable to provide a formal proof of identification in the presence of unobservables.

${ }^{14}$ Notice that when marriage and cohabitation are combined, there are no such peaks (see fig. 2). A possible explanation for this behavior is that individuals who are cohabiting want to celebrate their thirtieth or fortieth birthdays together with their marriage and time their marriage accordingly. 


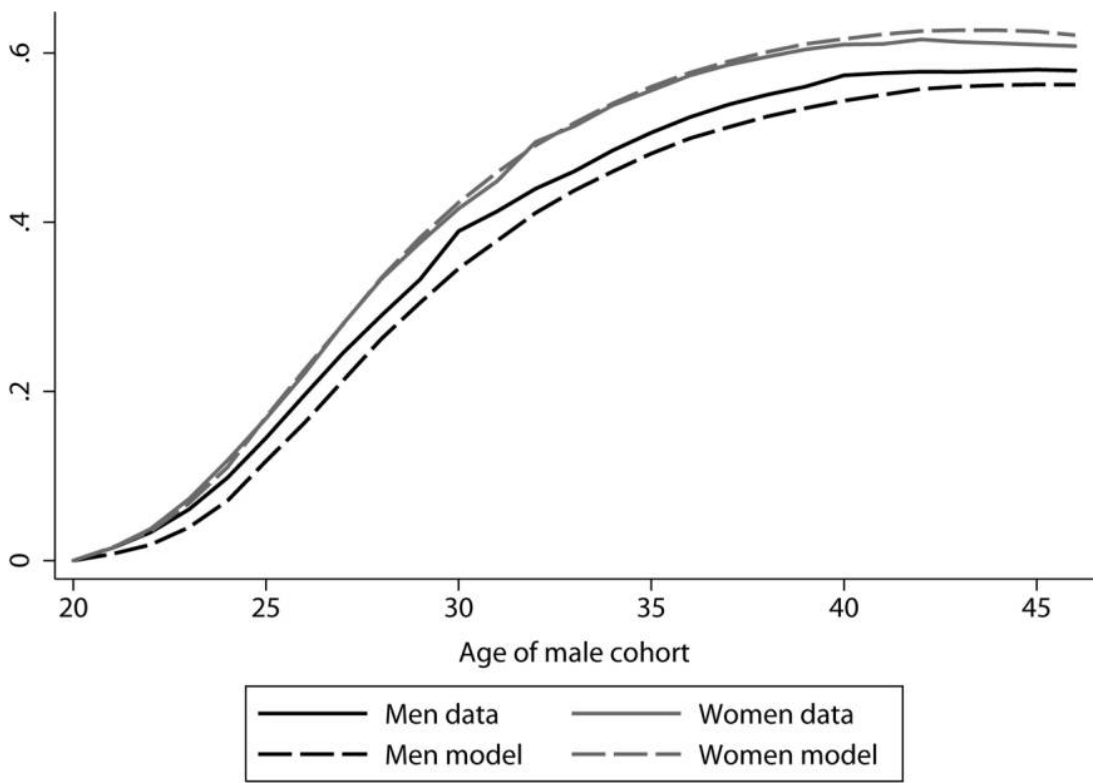

Fig. 11.-Fraction married in the data and in the model by gender. A color version of this figure is available online.

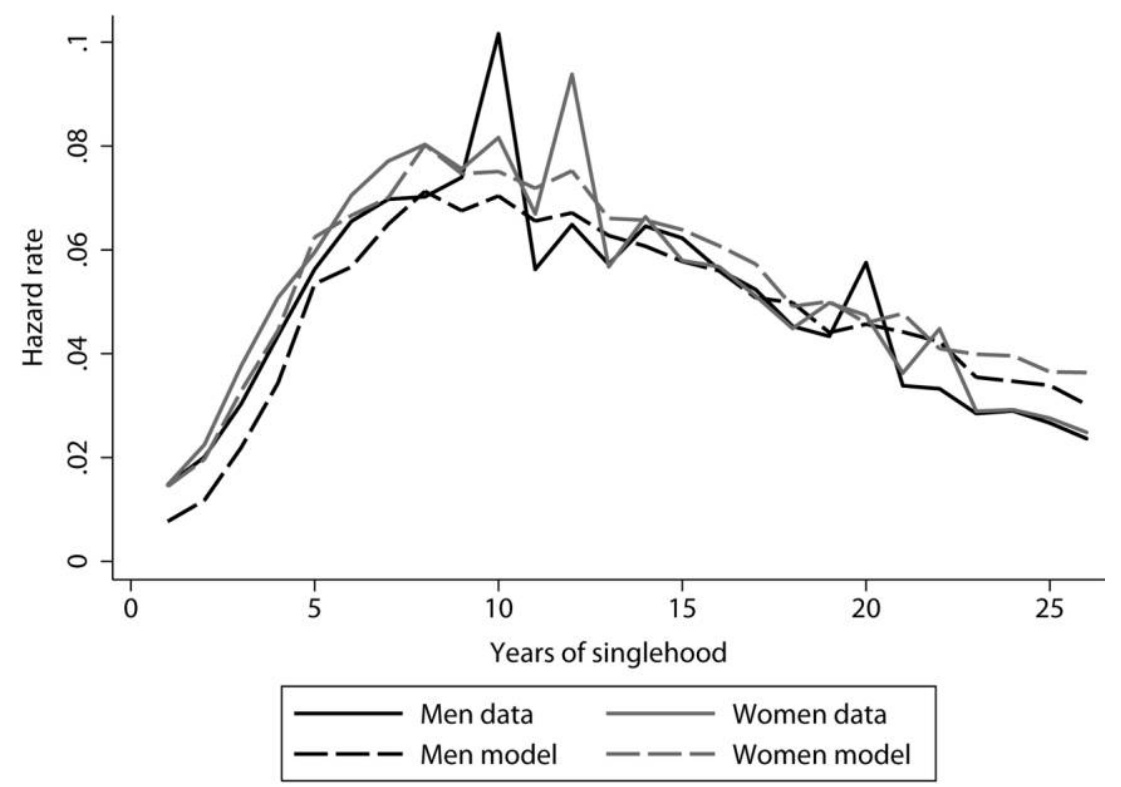

FIG. 12.- Hazard into first marriage in the data and in the model by gender. A color version of this figure is available online. 

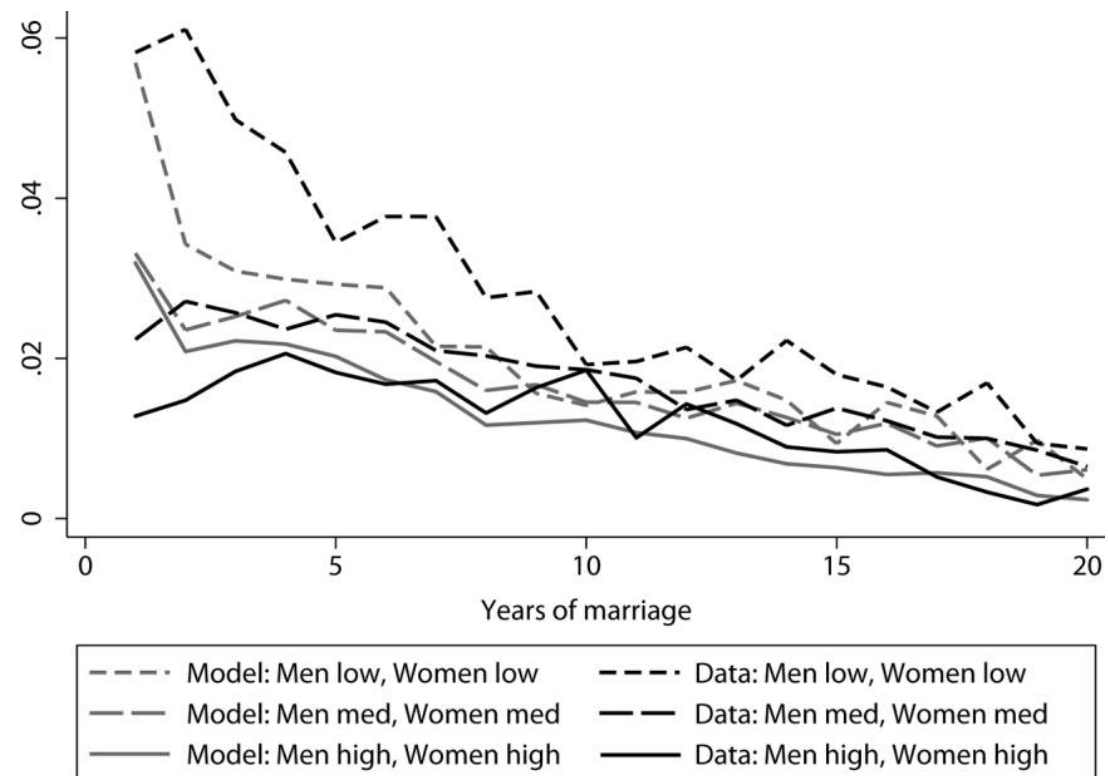

FIG. 13.-Divorce hazard for first marriage in the data and in the model by education and gender. A color version of this figure is available online.

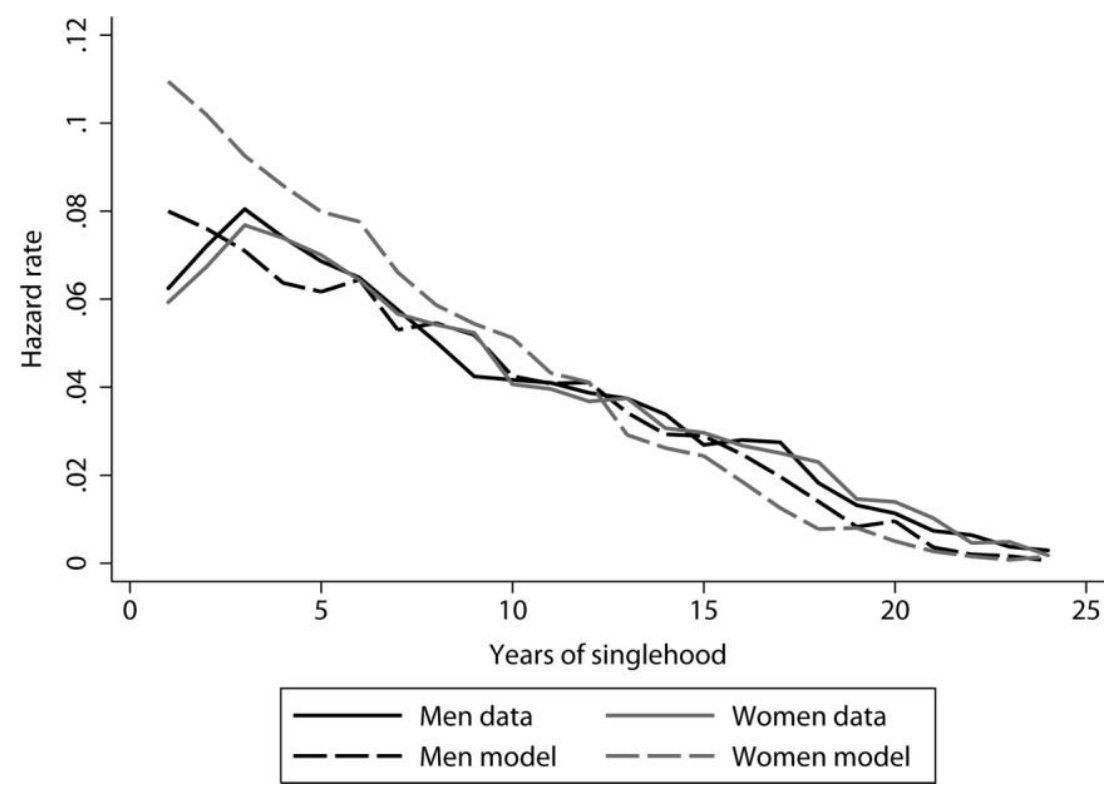

Fig. 14.- Hazard for entry into second or higher marriages in the data and in the model by gender. A color version of this figure is available online. 


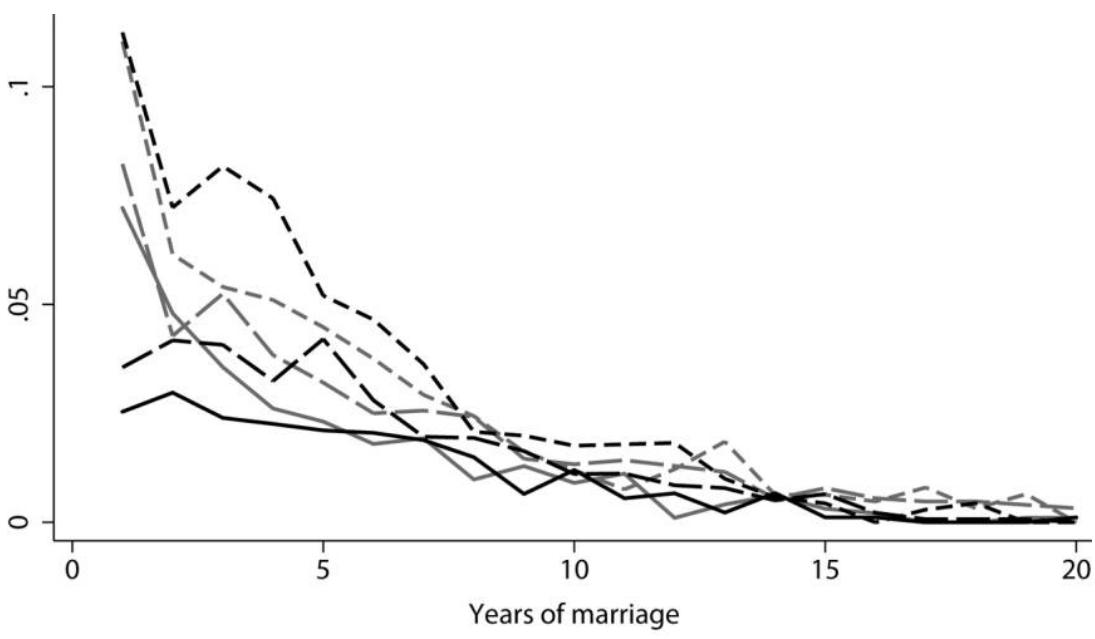

\section{- - - M Model: Men low, Women low $\quad---\cdot$ Data: Men low, Women low \\ - - Model: Men med, Women med — - Data: Men med, Women med \\ Model: Men high, Women high — Data: Men high, Women high}

FIG. 15.-Divorce hazard when at least one spouse is in second marriage, in the data and in the model by education and gender. A color version of this figure is available online.

To further examine the fit of the model, we compute the correlation between the ratio of estimated shares of the systematic marital surplus at the time of the marriage

$$
\frac{\gamma_{t}^{I J}}{1-\gamma_{t}^{I J}}
$$

and the relative male and female entry rates into different types of marriages at different points in time as observed in the data:

$$
\frac{\ln \left(\frac{\operatorname{Pr}(\text { single man of type } I \text { selects a wife of type } J \text { in year } t)}{\operatorname{Pr}(\text { single man of type } I \text { remains single in year } t)}\right)}{\ln \left(\frac{\operatorname{Pr}(\text { single woman of type } J \text { selects a husband of type } I \text { in year } t)}{\operatorname{Pr}(\text { single woman of type } J \text { remains single in year } t)}\right)}
$$

(the left- and right-hand sides of eq. [12]). The correlation between these two quantities is 0.86 when we use observations for all marriages. In some cases, the number of men and women who enter into marriage is so low that the data are very noisy. To reduce the effects of this noise, we remove marriages with only one male or one female entrant (less than $8 \%$ of the 
total number of observations). This increases the correlation to 0.89 . In figure 16, we also provide a scatter plot of the ratio of estimated share parameters and the observed relative entry rates into different types of marriages at different points in time. Figure 16 indicates that the estimated systematic share parameters $\gamma_{t}^{i j}$ are flexible enough to capture the observed variations in the relative male and female entry rates into marriage. The figure also provides a graphical illustration of how the systematic share parameters $\gamma_{t}^{i j}$ are identified in the data.

\section{B. The Marital Output Flow}

\section{Education}

Based on the estimated coefficients of equation (1), we can calculate the marital output flow by the education of the husband and wife. In table 2, we present this estimated flow when both spouses are in their first marriage.

There are two important features to notice about the marital output matrix in table 2. As one moves along the main diagonal in the table, the utility flow is lowest if both partners have a low education, then rises if both have medium education, and then reaches its highest point if both have high education. This monotonicity result is consistent with the high

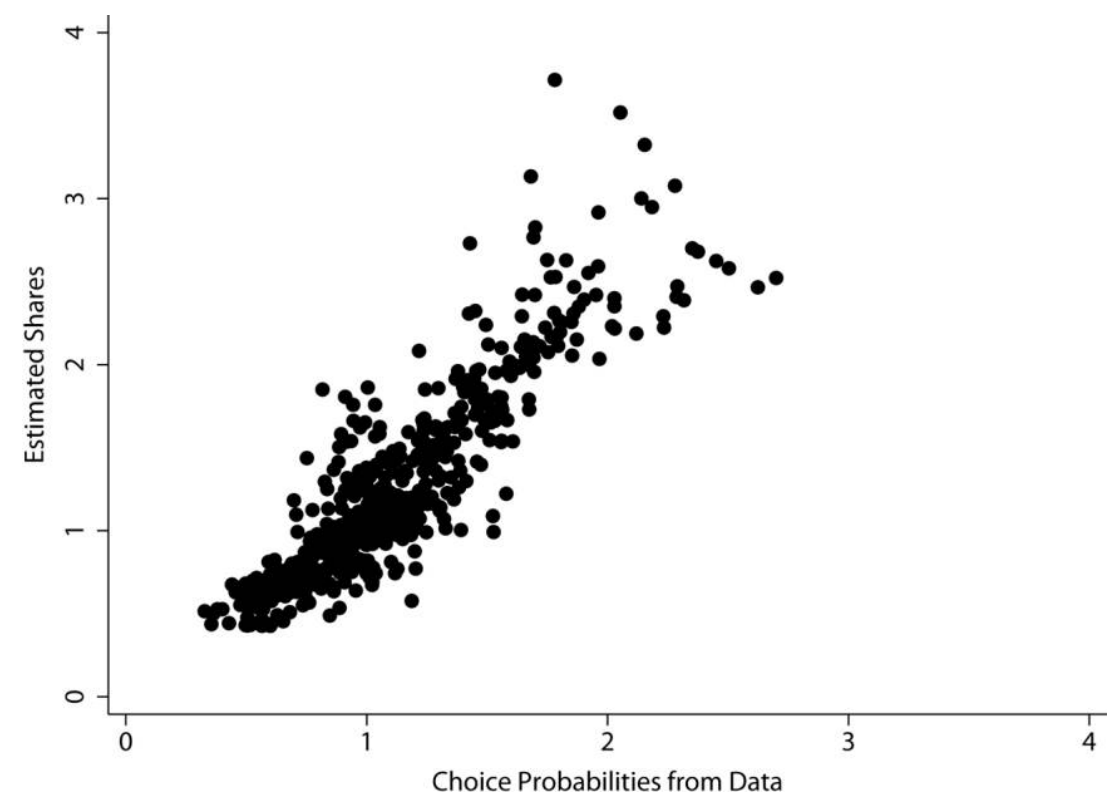

FIG. 16.- Ratio of estimated gammas and the log of male and female choice probabilities in the data. A color version of this figure is available online. 
rates of entry into marriage of highly educated men and women (especially at the later part of our sample) and the lower divorce rates for couples in which the two spouses are highly educated. The monotonicity result is significant at the $1 \%$ level.

Furthermore, our specification with additive utility implies that the supermodularity of husband and wife education in the marital output flow is independent of marriage order. We can therefore test for supermodularity by using the estimated coefficients in table 2. Denoting marriages by the education of the husband and the wife, this amounts to jointly testing if

$$
\begin{gathered}
(L, L)+(M, M)>(L, M)+(M, L), \\
(M, M)+(H, H)>(M, H)+(H, M), \\
(L, M)+(M, H)>(M, M)+(L, H), \\
(M, L)+(H, M)>(H, L)+(M, M) .
\end{gathered}
$$

Replacing these utility expressions with the estimated marriage output flows in first marriage, we find that all of these four inequalities hold at the estimated parameters.

$$
\begin{aligned}
-0.0079+0.0487 & >-0.0104+0.0023, \\
0.0487+0.1926 & >0.0700+0.0423, \\
-0.0104+0.0700 & >0.0487+0.0078, \\
0.0023+0.0423 & >-0.0072+0.0487 .
\end{aligned}
$$

Thus, the marital output flow that we have estimated is supermodular with respect to husband and wife education. This result is significant at the $1 \%$ level and rationalizes the high degree of sorting on education that we observe in our sample. Similar results are also reported by Siow (2009) and Chiappori et al. (2011) using US data.

\section{Marriage Order}

The marriage order of husbands and wives has a large impact on the estimated marital output flow (see table 3 ). Comparing marriages where both

Table 2

Estimated Marital Output Flows in First Marriage

\begin{tabular}{lccc}
\hline & \multicolumn{3}{c}{ Wife's Education } \\
\cline { 2 - 4 } Husband's Education & Low & Medium & High \\
\hline Low & -.0079 & -.0104 & .0078 \\
Medium & .0023 & .0487 & .0700 \\
High & -.0072 & .0423 & .1926 \\
\hline
\end{tabular}


Table 3

Effects of Marriage Order on the Marital Output Flow

\begin{tabular}{lcc}
\hline & Wife's First Marriage & Wife's Second Marriage \\
\hline Husband's first marriage & .5166 & .3891 \\
Husband's second marriage & .4709 & .5364 \\
\hline
\end{tabular}

spouses are of the same marriage order, table 3 indicates that the marital output flow is slightly higher when the husband and the wife are both marrying for the second or higher times. This finding is consistent with the fact that the hazards of entry into second marriages are higher than the hazards of entry into first marriages (see figs. 5 and 7).

In mixed marriages, there is a clear asymmetry between the two genders. A match of a divorced man with a woman who is married for the first time generates a higher marital output flow than a match of a divorced woman with a man who is married for the first time. ${ }^{15} \mathrm{~A}$ possible reason for this asymmetry is that divorced women bring children from previous marriages into their new marriages (see Beaujouan 2010).

\section{Utility Flow for Singles}

In order to estimate the systematic utility flow of single agents each period (see eq. [2] and eq. [3]), we use dummy variables based on age, gender, and education. When interpreting our estimates, it is important to recall the normalizations that we have made. In particular, we normalize the systematic utility flow of single men after age 40 to zero and the systematic utility flow of single women after age 38 to zero. Given these normalizations, we can analyze how the utility flows of single men and women change over time.

All of the estimated dummy coefficients for single agents are presented in the appendix. For single men in all education groups, the overall trend is that the utility flow falls over time. Stated differently, men are the least eager to marry when they are young but become more keen to marry as they get older. For single women in all education groups, the pattern is the opposite, that is, women are the most eager to marry when they are young and then become slightly less keen to marry as they get older. These results are consistent with the fertility rates of men and women over time. Women want to marry when they are young and their fertility is high, whereas men are more willing to delay their marriages.

${ }^{15}$ Both of these differences in marriage order coefficients mentioned above are significant at the $1 \%$ level. 


\section{Costs of Divorce}

The estimated costs of divorce are quite high and exceed half of the total capitalized value $W^{I J}$ of an ongoing marriage. ${ }^{16}$ Since we do not control directly for children and because the costs of separation are likely to rise over time as the average number of children rises, we would expect the costs of separation to rise with the duration of marriage. However, we do not find such an increasing trend. Rather, the divorce costs have a mild U-shape pattern with respect to duration (see table 4$).{ }^{17}$

\section{E. Unobserved Types}

Recall that in the specification of our dynamic model, we normalize the utility flow of single agents of Type 1 to zero, and we estimate the utility flow of single agents of Type 2 and the share of Type 2 agents in the population. Among men, a minority of $4 \%$ are estimated to be of Type 2 with a utility of being single of 0.405 . Among women, a majority of $91 \%$ are estimated to be of Type 2 with a utility of being single of -0.245 . These results indicate that both among men and women, a majority of individuals are of a type that weakly prefers marriage over singlehood and enter marriage quicker than one would expect based on observables such as education and age. To facilitate the discussion of our results, we henceforth refer to this type as "the marriage type" (Type 1 for men and Type 2 for women).

Following Eckstein and Wolpin (1999), we estimate the probability that each individual in our sample is of the marriage type using Bayes's rule. We then calculate the fraction of marriage types in subgroups of our sample by taking the average over these estimated probabilities, and we present our results in table 5. As can be seen in the table, the group of men and women who never marry contain fewer marriage types than the population of men and women at large. Furthermore, the group of men and women who enter into second marriage have a weaker unobserved preference for marriage than the group of men and women who enter into first marriage. This selection effect is especially strong for women, and it explains why second marriages are substantially less stable than first marriages even though the marital output flow is slightly higher in second marriages (see table 3 ). Stated differently, the high divorce rates in second marriages are to a large

${ }^{16}$ Seitz (2009) also finds high costs of divorce (about one-third of annual income).

${ }^{17}$ As our model does not include learning about the match quality, this shape can be driven in part by this omission. Early negative shocks are less likely to destroy the marriage if partners wait for more information in the future. In our model, this is captured by higher costs of divorce in early years. 
Table 4

\begin{tabular}{lc} 
Costs of Divorce by Duration of & Marriage \\
\hline Marital Duration & Cost of Divorce \\
\hline 1 year & 14.3 \\
2 years & 14.1 \\
3 years & 12.4 \\
4 years & 11.5 \\
5 years & 11.6 \\
6 years & 11.6 \\
7 years & 11.5 \\
8 years & 12.7 \\
9 years & 12.7 \\
10+ years & 12.7 \\
\hline
\end{tabular}

extent due to selection and not to the fact that second marriages are inherently less productive.

We then proceed by correlating the estimated probability that an agent is of the marriage type with a number of observed exogenous characteristics that we did not include in our model. In table 6, we show the results of this exercise. We first construct a dummy variable equal to one if the parents of the agent are living together in 1980. The Pearson correlation coefficient between this dummy and the estimated probability that the agent is of the marriage type is positive, indicating that agents whose parents are living together have a stronger preference for marriage. This finding indicates that there is a clear persistence across generations in decisions relating to marriage and divorce. We then assign the numerical values of 1 , 2 , and 3 to the parents of the agents depending on whether they have low, medium, or high education. We then compute the Spearman rank correlation coefficient between this index and the estimated probability that the agent is of the marriage type. As can be seen in table 6, the correlation is negative for both father's and mother's education. This negative correlation could reflect the fact that more educated agents marry later. Finally,

Table 5

Estimated Distribution of Type with Preference for Marriage over Singlehood

\begin{tabular}{lcc}
\hline & Men & Women \\
\hline Fraction, entire population & .961 & .914 \\
Fraction, never married & .875 & .710 \\
Fraction, married at least once & .991 & .886 \\
Fraction, divorced at least once & .971 & .657 \\
Fraction, married at least twice & .989 & .803 \\
Fraction, divorced at least twice & .965 & .543 \\
\hline
\end{tabular}


Table 6

Correlation Estimated Probability Agent Is of Marriage Type and Individual Characteristics

\begin{tabular}{lcc}
\hline Trait & Correlation & Number of observations \\
\hline Parents living together in 1980 & .054 & 56,353 \\
Father's completed education in 1980 & -.017 & 57,107 \\
Mother's completed education in 1980 & -.026 & 61,418 \\
Father's wealth in 1980 & .034 & 54,220 \\
\hline
\end{tabular}

we compute the Pearson correlation coefficient for father's wealth in 1980 and the estimated probability that an agent is of the marriage type. This correlation is positive, implying that agents whose fathers are wealthier are more likely to be married. All of the correlations listed in table 6 are significantly different from zero at the $1 \%$ level.

\section{F. Marital Surplus}

The systematic marital surplus $W_{t}^{I J}(1)-V_{t}^{I}-V_{t}^{J}$ varies by the education and the marriage order of the two spouses and by calender time (age of the two spouses). When presenting the main features of the estimated systematic marital surplus, we therefore form a weighted average of all estimated surpluses in different types of marriages, with weights derived from the relative frequencies of these marriages as predicted by our economic model.

In table 7, we first present the average marital surplus by the education of the husband and the wife. To construct this table, we formed a weighted average of all estimated marital surpluses occurring in different time periods and with spouses with different marital histories.

As can be seen in table 7, all of the systematic marital surpluses are negative. This absolute level of utility is arbitrary in our model and follows from the normalizations that we have made. More specifically, a single person can choose whether to remain single or marry into one of 12 different types of marriages. The proportion of men and women who enter into a particular type of marriage is usually smaller than the proportion remaining single. It then follows from the multinomial logit model that the utility of entering a particular marriage must be smaller than the utility of remaining single. Since we have normalized the flow utility of being single to zero at older ages, the value of being single is close to zero. All of this implies that the expected marital surplus must be negative. ${ }^{18}$

The meaningful content of table 7 is the differences between the marital surpluses in different types of marriages. Moving along the main diagonal

${ }^{18}$ In such a case, marriage is driven by the idiosyncratic preferences $\varepsilon$ of the partners. 
Table 7

Average Marital Surplus by Education of Husband and Wife

\begin{tabular}{lccc}
\hline & \multicolumn{3}{c}{ Wife's Education } \\
\cline { 2 - 4 } Husband's Education & Low & Medium & High \\
\hline Low & -14.94 & -14.92 & -14.99 \\
Medium & -14.88 & -14.80 & -14.89 \\
High & -14.93 & -14.85 & -14.77 \\
\hline
\end{tabular}

Table 8

Effects of Marriage Order on the Average Marital Surplus

\begin{tabular}{lcc}
\hline & Wife's First Marriage & Wife's Second Marriage \\
\hline Husband's first marriage & -14.89 & -14.90 \\
Husband's second marriage & -14.76 & -14.63 \\
\hline
\end{tabular}

in the table, we see that the marital surplus is increasing in the education of the husband and the wife in marriages where both spouses have the same education. We also test for the supermodularity of husband and wife education in the marital surplus. Three of the four inequalities (13) that characterize supermodularity hold at the estimated values of the surplus in table 7. This means that the surplus is supermodular at most but not all levels of education for the husband and the wife.

In table 8 , we present the average estimated marital surplus by the marriage order of the husband and the wife. To construct this table, we formed a weighted average of all estimated marital surpluses occurring in different time periods and with spouses with different levels of education. Comparing marriages where both spouses have the same marriage order, we see that the marital output flow is higher when both spouses are marrying for the second or higher times. In mixed marriages, a match of a divorced man with a woman who is married for the first time generates a higher marital output flow than a match of a divorced woman with a man married for the first time. Overall, the patterns of the estimated marital surplus are very similar to the patterns of the estimated marital output flow. This holds because the Bellman equations tie the asset value of marriage to its flow value.

\section{G. Total Surplus Shares}

In the estimation of our dynamic matching model, we obtain a set of parameters $\gamma_{t}^{I J}$ that describe the shares of the systematic marital surplus obtained by husbands and wives. These systematic shares apply to all men and women who enter into a particular type of marriage and do not depend on the idiosyncratic preferences $\varepsilon$ of individual men and women. In this sense, the systematic surplus shares $\gamma_{t}^{I J}$ characterize how the marital 
surplus would be divided between the husband and the wife if men and women were randomly sorted into different types of marriages.

A more meaningful approach is to analyze the sharing rule among men and women who decide to enter into a particular marriage on the basis of their idiosyncratic preferences $\varepsilon$. Such a modified sharing rule takes into account both the estimated shares $\gamma_{t}^{I J}$ and the optimal choices made by men and women in the marriage market. To obtain these modified shares for husbands and wives, we work with Bellman equations (6) and (7) for single men and women. Consider a single man who does not have the option to marry and therefore has to remain single in the next period. His expected utility is

$$
E_{t}\left(V_{t+1}^{I}+\varepsilon_{t+1}^{0}\right)=V_{t+1}^{I} .
$$

If instead the same man is allowed to enter into the marriage market in the next period, his expected utility is the continuation value

$$
C_{t+1}^{I} \equiv E_{t}\left[V_{t+1}^{I}+\max _{J \in E \times P_{t} \times U}\left\{\varepsilon_{t+1}^{0}, \gamma_{t+1}^{I J}\left[W_{t+1}^{I J}(1)-V_{t+1}^{I}-V_{t+1}^{J}\right]+\varepsilon_{t+1}^{J}\right\}\right] .
$$

Therefore, the expected gains from entering the marriage market for a man of type $I$ in period $t+1$ are

$$
C_{t+1}^{I}-V_{t+1}^{J}
$$

In a similar fashion, the expected gains from entering the marriage market for a woman of type $J$ in period $t+1$ are

$$
C_{t+1}^{J}-V_{t+1}^{J} \text {. }
$$

An important property of the multinomial logit model is that the expected gains from marriage, conditional on a particular choice of spouse, are the same for all choices of spouse and equal the unconditional expected gains from marriage (see Anas and Feng 1988; Chiappori et al. 2011). ${ }^{19}$ In addition, the independence of the idiosyncratic preferences for marriage $\varepsilon$ among men and women implies that the total expected gains from marriage of the husband and the wife equal the sum of the two spouses' individual gains $C_{t}^{I}-V_{t}^{I}+C_{t}^{J}-V_{t}^{J}$.

On the basis of these results, we define the share of the total expected gains to marriage of a man of type $I$ who marries a woman of type $J$ at time $t$ as

${ }^{19}$ This result is a consequence of the assumed IAA property, whereby the choice between any two alternatives in a given period depends only on their respective values (see Anas and Feng 1988). However, from a dynamic perspective, the logit model avoids the IAA property because the values of all future alternatives influence the value of each current alternative (see Rust 1994). 


$$
\Gamma_{t}^{I J}=\frac{C_{t}^{I}-V_{t}^{I}}{C_{t}^{I}-V_{t}^{I}+C_{t}^{J}-V_{t}^{J}} .
$$

In table 9, we present the estimated total shares of the husband $\Gamma$ in the expected gains to marriage as a function of the two spouses' education. To obtain these results, we form a weighted average of all estimated total surplus shares in marriages occurring in different time periods and with spouses who have or have not previously been married. The weights used for our calculation are the relative frequencies of these types of marriages as predicted by our economic model.

As can be seen in table 9, the husband's average share is slightly below half. Holding fixed the education of the wife, there is a clear tendency for men with higher education to receive a larger share of the gains to marriage. It is also striking that the education of the husband has a big impact on the share of the gains to marriage that he receives.

In table 10 , we present the estimated total shares of the wife $1-\Gamma$ in the gains to marriage as a function of the two spouses' education. Holding fixed the education of the husband, we see in table 10 that women with medium education receive the largest shares of the gains to marriage, whereas women with low education receive the smallest share. However, the total shares in table 10 do not vary much by the education of the wife, which indicates that the education of the wife has a smaller impact on the sharing rule than the education of the husband.

In table 11 below, we present the estimated total shares of the husband $\Gamma$ in the expected gains to marriage as a function of the two spouses' marital

Table 9

Estimated Average Total Surplus Share $\Gamma$ for Husband by Education of Husband and Wife

\begin{tabular}{lccc}
\hline & \multicolumn{3}{c}{ Wife's Education } \\
\cline { 2 - 4 } Husband's Education & Low & Medium & High \\
\hline Low & .417 & .387 & .402 \\
Medium & .496 & .463 & .490 \\
High & .530 & .493 & .498 \\
\hline
\end{tabular}

Table 10

Estimated Average Surplus Share $1-\Gamma$ for Wife by Education of Husband and Wife

\begin{tabular}{lccc}
\hline & \multicolumn{3}{c}{ Wife's Education } \\
\cline { 2 - 4 } Husband's Education & Low & Medium & High \\
\hline Low & .583 & .613 & .598 \\
Medium & .504 & .537 & .510 \\
High & .470 & .507 & .502 \\
\hline
\end{tabular}


Table 11

Estimated Average Total Surplus Share $\Gamma$ for Husband by Marital History of Husband and Wife

\begin{tabular}{lcc}
\hline & Wife's First Marriage & Wife's Second Marriage \\
\hline Husband's first marriage & .464 & .353 \\
Husband's second marriage & .563 & .455 \\
\hline
\end{tabular}

histories. To obtain these total shares, we once again form a weighted average of all estimated total surplus shares in marriages occurring in different time periods and between spouses with different levels of education.

Table 11 shows that the share of the husband is slightly below half when both spouses are marrying for the first time and when both spouses are marrying for the second or higher times. In marriages in which the two spouses have different marital histories, however, the spouse who is marrying for the second or higher times receives a substantially higher share. In the case of divorced men who are marrying never previously married women, a possible explanation for this higher share is that the men are slightly older than their wives and therefore have higher incomes. In the case of divorced women who are marrying never previously married men, it is good to recall from table 8 that the total surplus in this type of marriage is small. What table 11 indicates is that if such a marriage nevertheless occurs, it is the wife who receives the biggest benefits. A possible explanation is that the marriage is good for children that the wife has from previous relationships and that she is bringing into her new marriage.

Finally, table 12 presents the share of the husband in the expected gains to marriage as a function of time (the ages of the husband and the wife). The total shares in the table are weighted averages of all estimated total surplus shares in marriages occurring between spouses with different levels of education and with different marital histories. The total surplus shares by age (calender time) are available for a total of 26 years, but to save space we present these total shares at 5-year intervals.

As can be seen in table 12, the total share of the husband in the total marital surplus is increasing in the age of the husband. At younger ages,

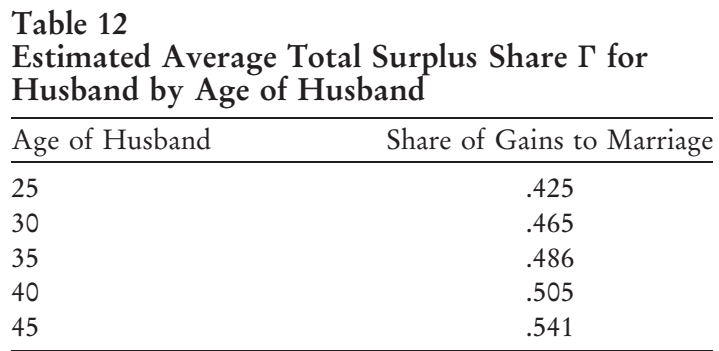


husbands receive less than half of the total marital surplus, whereas men age 40 or older receive more than half of the surplus. Equivalently, the results in table 12 show that the total share of the wife in the total marital surplus is decreasing in the age of the wife. The increasing shares of husbands are most likely due to a widening of the gender gap in wages and earnings as men and women get older, which in turn strengthens the position of men in the marriage market.

Many of the results on the total surplus shares that we obtain are similar to previous results on intrahousehold allocations reported in the collective household literature. For example, Bonke and Browning (2006) use detailed consumption data for Danish households and find that the mean share of husbands in total household consumption is close to a half. This is similar to our mean estimates of the share of the husband in the total marital surplus.

Bonke and Browning (2006) also examine how the wife's share of total household consumption depends on the difference between her and her husband's education. They find that wives receive a lower share of household consumption when their education exceeds the education of their husbands. Furthermore, Jacquemet and Robin (2012) use US data and examine how intrahousehold allocations depend on the husband's and wife's wages. They find that the wage rate of men has a strong and positive effect on the share of resources obtained by husbands in marriage. In contrast, the wage rate of women has a small effect on the share of resources obtained by wives. This effect is positive for most of the support of female wages, but it turns negative for very high female wages. All these results resemble the total surplus shares that we obtain in this paper as a function of husband's and wife's educations.

The biggest difference between our results and previous results has to do with the effect of previous marriages and children on intrahousehold allocations. Browning and Bonke (2006) estimate that wives who have previously been married and who have children from previous relationships receive a smaller share of total household consumption than wives without previous marriages and children. In contrast, we find that divorced women receive the same or a higher share of the total marital surplus. Our best reconciliation of these results is that the total surplus shares that we estimate are different from the shares of total household consumption and leisure estimated in the collective household literature. For example, a divorced woman with a child may benefit more from a second marriage than her husband due to the positive effect that the marriage has on her child. This benefit to the wife is part of the total surplus in marriage, but it does not directly enter into the measured shares of household consumption and leisure. Our approach is in this sense more inclusive as it is based on the choices to marry and to remain married. 


\section{H. Copenhagen Sample}

We recognize that the systematic $\gamma$ and total surplus shares $\Gamma$ may differ across marriage markets with different distributions of types even if individual preferences over types remain constant. We therefore construct an alternative sample of men who resided in the Copenhagen area at least during ages 25-30 and women who resided in the Copenhagen area at least during ages 23-28. The distribution of agents in this sample by gender and education is shown in table 13 below. Comparing with table 1 for the Denmark sample, we see that there are substantially more highly educated men and women in Copenhagen than in Denmark as a whole and fewer men and women with medium education. We also note that whereas there are more women than men both in Denmark as a whole and in Copenhagen, the fraction of women is highest in Copenhagen.

We then reestimate the model for the Copenhagen sample under the restriction that all parameters are the same as those estimated from the Denmark sample, except for the distribution of the unobserved utility of being single and the systematic surplus shares $\gamma$ in marriage. In table 14 below, we show the estimated average total surplus shares $\Gamma$ of the husband by the education of both spouses. Comparing these total surplus shares with the estimates in table 9 for the Denmark sample, we see that the main features of the sharing rule are preserved also in this sample. One important difference however, is that men receive a higher share of the

Table 13

Sample Distribution of Male and Female Completed Education in Copenhagen Sample

\begin{tabular}{lcc}
\hline Completed Education (at Age 46) & Men & Women \\
\hline High school or less & 32.6 & 26.3 \\
Vocational education & 34.0 & 33.5 \\
Some college or more & 33.4 & 40.3 \\
No. of observations & 5,670 & 5,949 \\
\hline
\end{tabular}

Table 14

Estimated Average Surplus Share $\Gamma$ for Husband by Education of Husband and Wife in Copenhagen Sample

\begin{tabular}{lccc}
\hline & \multicolumn{3}{c}{ Wife's Education } \\
\cline { 2 - 4 } Husband's Education & Low & Medium & High \\
\hline Low & .458 & .421 & .424 \\
Medium & .535 & .502 & .520 \\
High & .593 & .559 & .540 \\
\hline
\end{tabular}


surplus in the Copenhagen sample. This is consistent with the more favorable sex ratio for men in this region.

\section{Changing the Definition of Marriage}

In the baseline estimation of our model above, we used a definition of marriage that did not include cohabiting couples. Stated differently, we treated the group of men and women who cohabit without being married as if they were singles. In this section, we present the results of a robustness check in which we estimate our model using a definition of marriage which includes cohabiting couples (partnerships).

\section{Sample}

In the selection of our baseline sample, we dropped all the 725 men and women who were married in 1980 . To be consistent, we construct our alternative sample by dropping all the men and women who were either married or cohabiting in 1980. Since the group of men and women who were either married or cohabiting in 1980 is larger than the group of men and women who were married in 1980, we end up with an alternative sample that is smaller than the baseline sample. The alternative sample is a subset of the baseline sample (the baseline sample minus the men and women who cohabited in 1980) and consists of 54,308 individuals.

\section{Results}

All of the estimated parameters from our alternative model are presented in the appendix (the column labeled Partnerships) next to the estimated parameters from the baseline model (the column labeled Marriages). The quality of fit of the model estimated on the alternative sample is good, except for the entry into first partnerships where the model overpredicts entry at later ages. As in the baseline model, unobserved heterogeneity is an important component that improves the fit. We find that the difference in the utility of being single between Type 1 and Type 2 agents is bigger in the alternative model. Thus, compared to marriages, more heterogeneity is required to explain the dynamics of partnerships.

As can be seen in the appendix, most of the estimated parameters for the output flow in marriage are higher in the alternative model. Also, most estimated parameters for the utility flow in singlehood are lower in the alternative model. These two changes are due to the fact that a smaller fraction of agents are defined as being single in the alternative sample. The model rationalizes this alternative composition of men and women by making the marital surplus bigger (by increasing the utility flow of married couples and by decreasing the utility of being single).

Just as in the baseline model, the estimated marital output flow is increasing in education along the main diagonal of the output matrix in the 
alternative model. Furthermore, the marital output flow is still supermodular with respect to husband's and wife's education. These findings are consistent with the fact that the assignment patterns in partnerships are very similar to the assignment patterns in marriage (see our discussion in Sec. III.D).

The effects of marriage order on the marital output flow in the alternative model are similar to those in the baseline model. Comparing partnerships in which none of the spouses have previously divorced with those in which both spouses have previously divorced, the utility flow is still highest if both spouses have previously divorced. However, this difference is more pronounced for partnerships than for marriages, which could be due to the fact that many first partnerships are experimental in nature and do not last for a long time. Comparing mixed partnerships to each other, the output flow is lowest when a divorced woman is in a partnership with a man who has not previously divorced.

The estimated time patterns for the utility of singlehood are the same in the alternative and the baseline models. For men, the utility of being single is falling over time, which implies that men become more eager to marry as they get older. For women, the utility of being single increases over time, which implies that women become less eager to marry as they get older.

Under our baseline definition of marriage, the costs of divorce follow a mild U-shape pattern with respect to the duration of the marriage, but this effect is rather weak. In the alternative model, the pattern is different as the cost of divorce increases with the duration of the partnership. We cannot say on the basis of our estimates if this increasing pattern is due to a process of learning that weeds out the partnerships with the highest match quality or if the pattern is due to the gradual build-up of partnershipspecific capital such as children and common property. What our results suggest, though, is that marriages and cohabitation are different with respect to these two dynamic processes (learning and the build-up of relationshipspecific capital).

\section{Summary}

Overall, our estimates from the alternative sample indicate that most of the main results in this paper are not sentitive to how we define marriage versus singlehood. The differences in the divorce hazards for marriages and partnerships and the differences in the time patterns of the estimated divorce costs for marriages and partnerships do suggest, however, that there are important differences between marriage and cohabitation. Since many couples in Denmark cohabit prior to marriage (see Svarer 2004), a model that addresses the choice between marriage and cohabitation should arguably involve an explanation of why some couples cohabit and then divorce, why some transition from cohabitation to marriage, and why some 
remain cohabiting for the rest of their lives without getting married. Two dynamic processes that are likely to be important for the potential transition from cohabitation to marriage are learning about match quality (see Brien et al. 2006) and the build-up of relationship-specific capital such as children. A full model that incorporates these processes and different divorce costs in marriage and cohabitation, as well as the dynamics of marriage and divorce that we have highlighted, is an interesting topic for future research but is beyond the scope of this paper.

\section{Conclusion}

In this paper, we study the complex interactions between marriage, divorce, and assortative matching within two cohorts of Danish men and women that we follow from 1980 to 2006 . We start by describing several important features of the dynamic process of marriage and divorce (some of which have also been documented in previous research). For example, we find that the marriage rates of Danish men and women with low education are substantially below those of other education groups. This is especially true for men. Those men and women who divorce are eager to marry, and the initial hazards of entry into second marriage exceed those for first marriage. However, second marriages are substantially less stable than first marriages.

We then estimate a dynamic matching model that allows us to analyze the interdependent marital choices of many individuals over a large part of their lifetime (ages 20-46 for men and ages 18-44 for women) on the basis of a small number of key parameters. These parameters include the joint utility flow in different types of marriages, the shares of the systematic marital surplus that husbands and wives receive, the costs of divorce, and individual fixed preferences for marriage versus singlehood. Our model allows for a rich heterogeneity in types of agents, and we distinguish between men and women with different levels of completed education and different marital histories.

The estimates from our dynamic two-sided matching model reveal that the effects of education on the sharing rule in marriage is different for men and women. Among men, education raises the share of the marital surplus, whereas it is women with medium education who receive the largest shares of the marital surplus. The high degree of assortative matching in our sample can in part be rationalized by the complementarity of husband's and wife's education in marriage. Furthermore, our estimates indicate that the cost of divorce is high relative to the capitalized value of an ongoing marriage. We also find that the higher divorce rates in second marriage are almost entirely driven by a dynamic selection process in which men and women with a weaker preference for marriage are more likely to divorce and then marry a second time. 
An important issue that we do not analyze is what mechanisms generate the poor outcomes in marriage for Danish men and women with low education. An open issue is whether these differences are due to the financial situation of different types of households or if there are other important mechanisms at work as well. However, we do find that these differences in outcomes across educational groups are also present in cohabitation.

\section{Appendix}

\section{Table A1}

\section{Estimated Coefficients}

\begin{tabular}{|c|c|c|c|c|}
\hline & \multicolumn{2}{|c|}{ Marriages } & \multicolumn{2}{|c|}{ Partnerships } \\
\hline & Coefficient & SE & Coefficient & $\mathrm{SE}$ \\
\hline \multicolumn{5}{|l|}{ Marital output flow by education: } \\
\hline Husband's low, wife's low & -.525 & $2.74 \mathrm{E}-04$ & -.542 & $8.23 \mathrm{E}-04$ \\
\hline Husband's low, wife's medium & -.527 & $6.74 \mathrm{E}-04$ & -.455 & $2.68 \mathrm{E}-04$ \\
\hline Husband's low, wife's high & -.509 & $4.55 \mathrm{E}-04$ & -.403 & $2.73 \mathrm{E}-04$ \\
\hline Husband's medium, wife's low & -.514 & $2.77 \mathrm{E}-04$ & -.531 & $2.71 \mathrm{E}-04$ \\
\hline Husband's medium, wife's medium & -.468 & $2.73 \mathrm{E}-04$ & -.385 & $2.73 \mathrm{E}-04$ \\
\hline Husband's medium, wife's high & -.447 & $2.78 \mathrm{E}-04$ & -.330 & $2.78 \mathrm{E}-04$ \\
\hline Husband's high, wife's low & -.524 & $2.73 \mathrm{E}-04$ & -.588 & $2.79 \mathrm{E}-04$ \\
\hline Husband's high, wife's medium & -.474 & $2.71 \mathrm{E}-04$ & -.440 & $2.83 \mathrm{E}-04$ \\
\hline Husband's high, wife's high & -.324 & $2.71 \mathrm{E}-04$ & -.178 & $2.79 \mathrm{E}-04$ \\
\hline \multicolumn{5}{|l|}{ Marital output flow by marriage order: } \\
\hline 1 st marriage for both spouses & .517 & $2.52 \mathrm{E}-04$ & .530 & $2.27 \mathrm{E}-04$ \\
\hline Husband's 1st, wife's 2nd marriage & .389 & $2.64 \mathrm{E}-04$ & .393 & $2.49 \mathrm{E}-04$ \\
\hline Husband's 2nd, wife's 1st marriage & .471 & $2.46 \mathrm{E}-04$ & .592 & $2.09 \mathrm{E}-04$ \\
\hline 2nd marriage for both spouses & .536 & $2.52 \mathrm{E}-04$ & .648 & 2.37E-04 \\
\hline \multicolumn{5}{|l|}{ Cost of divorce: } \\
\hline 1 year of marriage & 14.30 & $3.19 \mathrm{E}-04$ & 9.41 & $9.14 \mathrm{E}-05$ \\
\hline 2 years of marriage & 14.13 & $1.23 \mathrm{E}-03$ & 14.60 & $1.53 \mathrm{E}-03$ \\
\hline 3 years of marriage & 12.39 & $1.18 \mathrm{E}-03$ & 13.56 & $1.08 \mathrm{E}-03$ \\
\hline 4 years of marriage & 11.54 & $1.07 \mathrm{E}-03$ & 14.36 & $1.19 \mathrm{E}-03$ \\
\hline 5 years of marriage & 11.57 & $1.03 \mathrm{E}-03$ & 15.96 & $1.78 \mathrm{E}-03$ \\
\hline 6 years of marriage & 11.63 & $1.07 \mathrm{E}-03$ & 16.07 & $1.65 \mathrm{E}-03$ \\
\hline 7 years of marriage & 11.50 & $1.08 \mathrm{E}-03$ & 17.21 & $2.74 \mathrm{E}-03$ \\
\hline 8 years of marriage & 12.69 & $1.09 \mathrm{E}-03$ & 19.78 & $2.72 \mathrm{E}-03$ \\
\hline 9 years of marriage & 12.67 & $1.11 \mathrm{E}-03$ & 20.37 & $1.83 \mathrm{E}-03$ \\
\hline $10+$ years of marriage & 12.66 & 8.57E-04 & 20.35 & $1.30 \mathrm{E}-03$ \\
\hline \multicolumn{5}{|l|}{ Utility male singles: } \\
\hline Man, 20-21, low education & 1.083 & $.0606)$ & .922 & $8.92 \mathrm{E}-03$ \\
\hline Man, 22-23, low education & .732 & $.0398)$ & .334 & 7.17E-03 \\
\hline Man, 24-26, low education & .310 & $5.44 \mathrm{E}-03$ & .234 & 4.27E-03 \\
\hline Man, 27-30, low education & .378 & $2.06 \mathrm{E}-03$ & .470 & $1.53 \mathrm{E}-03$ \\
\hline Man, 31-35, low education & .0321 & $9.24 \mathrm{E}-03$ & .103 & $3.86 \mathrm{E}-03$ \\
\hline Man, 36-40, low education & .0363 & $1.09 \mathrm{E}-03$ & .282 & $1.75 \mathrm{E}-03$ \\
\hline
\end{tabular}


Table A1 (Continued)

\begin{tabular}{|c|c|c|c|c|}
\hline & \multicolumn{2}{|c|}{ Marriages } & \multicolumn{2}{|c|}{ Partnerships } \\
\hline & Coefficient & SE & Coefficient & SE \\
\hline Man, 20-21, medium education & 2.081 & $.0606)$ & 1.022 & $8.91 \mathrm{E}-03$ \\
\hline Man, 22-23, medium education & .749 & $.0398)$ & .310 & 7.17E-03 \\
\hline Man, 24-26, medium education & .329 & $5.43 \mathrm{E}-03$ & .215 & $4.29 \mathrm{E}-03$ \\
\hline Man, $27-30$, medium education & .372 & $2.06 \mathrm{E}-03$ & .436 & $1.55 \mathrm{E}-03$ \\
\hline Man, 31-35, medium education & -.0181 & $9.23 \mathrm{E}-03$ & .0368 & $3.87 \mathrm{E}-03$ \\
\hline Man, 36-40, medium education & -.0303 & $1.08 \mathrm{E}-03$ & .0689 & $1.75 \mathrm{E}-03$ \\
\hline Man, 20-21, high education & 2.334 & .0607 & 1.438 & $8.91 \mathrm{E}-03$ \\
\hline Man, 22-23, high education & 1.138 & .0398 & .750 & $7.15 \mathrm{E}-03$ \\
\hline Man, 24-26, high education & .623 & $5.43 \mathrm{E}-03$ & .448 & $4.27 \mathrm{E}-03$ \\
\hline Man, 27-30, high education & .502 & $2.06 \mathrm{E}-03$ & .414 & $1.55 \mathrm{E}-03$ \\
\hline Man, 31-35, high education & -.0300 & $9.23 \mathrm{E}-03$ & -.0154 & $3.88 \mathrm{E}-03$ \\
\hline Man, 36-40, high education & $-3.47 \mathrm{E}-03$ & $1.08 \mathrm{E}-03$ & .215 & $1.75 \mathrm{E}-03$ \\
\hline \multicolumn{5}{|l|}{ Utility female singles: } \\
\hline Woman, $18-19$, low education & -.743 & .0606 & -.752 & $8.91 \mathrm{E}-03$ \\
\hline Woman, 20-21, low education & -.145 & .0398 & -.525 & $7.16 \mathrm{E}-03$ \\
\hline Woman, 22-24, low education & -.196 & $5.43 \mathrm{E}-03$ & -.297 & $4.29 \mathrm{E}-03$ \\
\hline Woman, 25-28, low education & -.391 & $2.04 \mathrm{E}-03$ & -.443 & $1.55 \mathrm{E}-03$ \\
\hline Woman, 29-33, low education & .0342 & $9.23 \mathrm{E}-03$ & .140 & $3.86 \mathrm{E}-03$ \\
\hline Woman, 34-38, low education & .0215 & $1.08 \mathrm{E}-03$ & $-3.66 \mathrm{E}-03$ & $1.75 \mathrm{E}-03$ \\
\hline Woman, $18-19$, medium education & -.135 & .0606 & -.758 & $8.91 \mathrm{E}-03$ \\
\hline Woman, 20-21, medium education & .207 & .0398 & -.438 & $7.15 \mathrm{E}-03$ \\
\hline Woman, 22-24, medium education & -.207 & $5.44 \mathrm{E}-03$ & -.329 & 4.27E-03 \\
\hline Woman, 25-28, medium education & -.411 & $2.04 \mathrm{E}-03$ & -.464 & $1.54 \mathrm{E}-03$ \\
\hline Woman, 29-33, medium education & -.0118 & $9.23 \mathrm{E}-03$ & .0631 & $3.87 \mathrm{E}-03$ \\
\hline Woman, 34-38, medium education & $-6.02 \mathrm{E}-03$ & $1.08 \mathrm{E}-03$ & .0845 & $1.75 \mathrm{E}-03$ \\
\hline Woman, 18-19, high education & .0870 & .0606 & -.585 & $8.91 \mathrm{E}-03$ \\
\hline Woman, 20-21, high education & .452 & $.0398)$ & -.195 & $7.16 \mathrm{E}-03$ \\
\hline Woman, 22-24, high education & $-3.74 \mathrm{E}-03$ & $5.43 \mathrm{E}-03$ & -.211 & $4.28 \mathrm{E}-03$ \\
\hline Woman, 25-28, high education & -.307 & $2.05 \mathrm{E}-03$ & -.332 & $1.55 \mathrm{E}-03$ \\
\hline Woman, 29-33, high education & .0263 & $9.23 \mathrm{E}-03$ & .0112 & $3.87 \mathrm{E}-03$ \\
\hline Woman, 34-38, high education & $-9.25 \mathrm{E}-04$ & $1.08 \mathrm{E}-03$ & .226 & $1.75 \mathrm{E}-03$ \\
\hline \multicolumn{5}{|l|}{ Unobserved heterogeneity: } \\
\hline Utility $u_{2}$ men & .405 & $7.60 \mathrm{E}-05$ & 616 & $5.44 \mathrm{E}-05$ \\
\hline Fraction Type 2 men & .0393 & $4.44 \mathrm{E}-05$ & .0517 & 2.07E-05 \\
\hline Utility $u_{2}$ women & -.245 & $2.13 \mathrm{E}-05$ & -.564 & $5.11 \mathrm{E}-05$ \\
\hline Fraction Type 2 women & .914 & $5.30 \mathrm{E}-05$ & .943 & 2.17E-05 \\
\hline
\end{tabular}

\section{References}

Aiyagari, Rao S., Jeremy Greenwood, and Nezih Guner. 2000. On the state of the union. Lournal of Political Economv 108:213-44.

Anas, Alex, and Cheng M. Feng. 1988. Invariance of expected utilities in logit models. Economic Letters 27:41-45.

Beaujouan, Eva. 2010. Children at home, staying alone? Paths towards repartnering for men and women in France. Centre for Population Change Working Paper 4, University of Southampton. 
Becker, Gary S., Elisabeth M. Landes, and Robert T. Michael. 1977. An economic analysis of marital instability. Journal of Political Economy 85:1141-87.

Brien, Michael J., Lee A. Lillard, and Steven Stern. 2006. Cohabitation, marriage, and divorce in a model of match quality. International Economic Review 47:451-94.

Browning, Martin, and Jens Bonke. 2006. Allocation within the household: Direct survey evidence. Discussion Paper 429, Department of Economics, Oxford University.

Browning, Martin, and Mette Gørtz. 2012. Spending time and money within the household. Scandinavian Journal of Economics 114:681-704.

Browning, Martin, Francois Bourguignon, Pierre-André Chiappori, and Valerie Lechene. 1994. Income and outcomes: A structural model of intrahousehold allocation. Journal of Political Economy 102:1067-96.

Browning, Martin, Pierre-André Chiappori, and Yoram Weiss. 2014. Economics of the family. New York: Cambridge University Press.

Chiappori, Pierre-André. 1988. Rational household labor supply. Econometrica 56:63-90.

Chiappori, Pierre-André, Murat Iyigun, and Yoram Weiss, 2007. Public goods, transferable utility and divorce Laws. IZA Discussion Papers 2646, Institute for the Study of Labor (IZA), Germany.

Chiappori, Pierre-André, Bernard Salanie, and Yoram Weiss. 2011. Partner choice and the marital college premium. Department of Economics Discussion Papers 1011-04, Columbia University, New York.

Choo, Eugene. 2012. Dynamic marriage matching: An empirical framework. Working paper. Department of Economics, University of Calgary, Canada.

Choo, Eugene, and Aloysius Siow. 2006. Who marries whom and why. Journal of Political Economy 114:175-201.

. 2007. Lifecycle marriage matching: Theory and evidence. Society for Economic Dynamics Meeting Paper 550.

Copen, Casey E., Kimberly Daniels, Jonathan Vespa, and William D. Mosher. 2012. First marriages in the United States: Data from the 20062010 National Survey of Family Growth. National Health Statistics Reports, no. 49. US Department of Health and Human Services.

Eckstein, Zvi, and Kenneth I. Wolpin. 1999. Why do youths drop out of high school? The impact of preferences, opportunities, and abilities. Econometrica 67:1295-1339.

Ge, Suqin. 2011. Women's college decisions: How much does marriage matter? Journal of Labor Economics 29:773-818.

Gemici, Ahu, and Steven Laufer. 2011. Marriage and cohabitation. Working Paper, Department of Economics, New York University.

Graham, Bryan. 2011. Econometric methods for the analysis of assignment problems in the presence of complementarity and social spillovers. 
In Handbook of social economics, ed. Jess Benhabib, Alberto Bisin, and Matthew O. Jackson. Amsterdam: Holland, Elsevier.

Isen, Adam, and Betsey Stevenson. 2010. Women's education and family behavior: Trends in marriage, divorce and fertility. In Demography and the economy, ed. John B. Shoven. Chicago: University of Chicago Press. Jacquemet, Nicolas, and Jean-Marc Robin. 2012. Assortative matching and search with labor supply and home production. Working paper, Sciences Po, France.

Martin, Steven P. 2012. Growing evidence for a "divorce divide"? Education and marital dissolution rates in the U.S. since the 1970s. Working paper, Department of Sociology, University of Maryland, College Park.

Mazzocco, Maurizio, Claudia Ruiz, and Shintaro Yamaguchi. 2007. Labor supply, wealth dynamics, and marriage decisions. Working paper, Department of Economics, University of California, Los Angeles.

McFadden, Daniel L. 1984. Econometric analysis of qualitative response models. In Handbook of econometrics, ed. Zvi Griliches and Michael D. Intriligator. Amsterdam: Holland, Elsevier.

Parisi, Lavinia. 2008. The hazards of partnership dissolution in Britain: A comparison between second and first marriages. ISER working paper, University of Essex.

Rust, John. 1994. Structural estimation of Markov decision processes. In Handbook of econometrics, ed. Robert F. Engle and Daniel McFadden. Amsterdam: Holland, Elsevier.

Seitz, Shannon. 2009. Accounting for racial differences in marriage and employment. Journal of Labor Economics 27:385-437.

Siow, Aloysius. 2008. How does the marriage market clear? An empirical framework. Canadian Journal of Economics 41:1121-55.

- 2009. Testing Becker's theory of positive assortative matching. Working paper, Department of Economics, University of Toronto.

Stevenson, Betsey, and Justin Wolfers. 2007. Marriage and divorce: Changes and their driving forces. Journal of Economic Perspectives 21:27-52.

Svarer, Michael. 2004. Is your love in vain? Another look at premarital cohabitation and divorce. Journal of Human Resources 39:523-35.

Weiss, Yoram, and Robert J. Willis. 1997. Match quality, new information, and marital dissolution. Journal of Labor Economics 15, suppl.: S293-S329. 